\title{
وسطية الإسلام فى مجتمع متعدد الثقافات \\ المجتمع الإندونيسي نموذجا
}

\author{
إعداد الباحث/ حمحة أنيق \\ Muhammad Aniq \\ STIQ Islamic Centre Demak \\ aniq_imam@yahoo.com
}




\begin{abstract}
Multiculturalism is the cultural diversity of communities within a given society and the policies that promote this diversity. As a descriptive term, multiculturalism is the simple fact of cultural diversity and the demographic make-up of a specific place, sometimes at the organizational leve. As a prescriptive term, multiculturalism encourages ideologies and policies that promote this diversity or its institutionalization. In this sense, multiculturalism is a society "at ease with the rich tapestry of human life and the desire amongst people to express their own identity in the manner they see fit. This paper discusses multicultural ideologies or policies vary widely, ranging from the advocacy of equal respect to the various cultures in a society, to a policy of promoting the maintenance of cultural diversity, to policies in which people of various ethnic and religious groups are addressed by the authorities as defined by the group they belong to.

Pluralism, diversity and multiculturalism is a daily fact of life in Indonesia. There are over 300 ethnic groups in Indonesia. The Javanese is the largest ethnic group in Indonesia who make up nearly $42 \%$ of the total population. The Sundanese, Malay, and Madurese are the next largest groups in the country. There are also more than 700 living languages spoken in Indonesia and although predominantly Muslim the country also has large Christian and Hindu populations. This paper also uncloses the model of Islamic Moderation in Indonesia societies in the light of Various Cultures and Relegion.
\end{abstract}


مقدمة :

تهدف هذه الورقة العملية إلى تقديم معالم الوسطية الإسلامية بخصوص موضوع تعدد الثقافات في

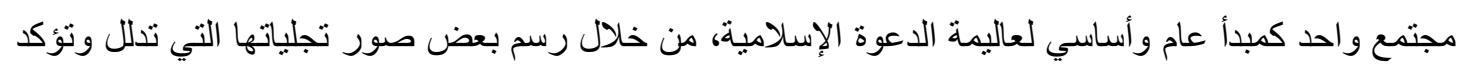

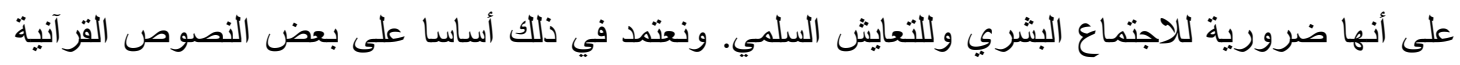
والسنة النبوية في عرض وتحليل هذه الفكرة. فالتركيز هنا ينصرف في المقام الأول إلى التعدد الديني والثقافي

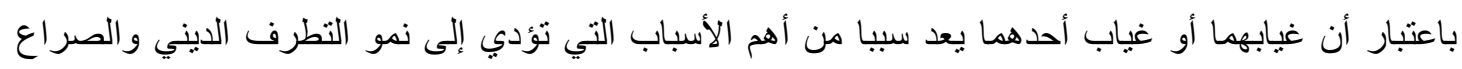
الحضاري في العالم الحالي. وبتعبير آخر تتطلع هذه المقالة إلى إلقاء الضوء على على طبيعة التفاعل الحضاري و النقافي الذي ينبغي أن يسود بين الثعوب و المجتمعات والأمم من وجهة نظر الوسطية الإسلامية. لقد أرسى الإسلام دعائم وقو اعد ومبادئ للتعايش السلمي بين الناس جميعا .ودعا المسلمين إلى مخاطبة

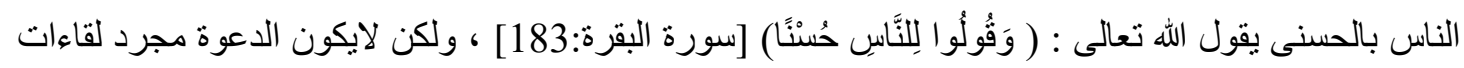

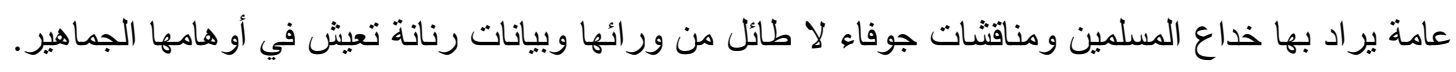

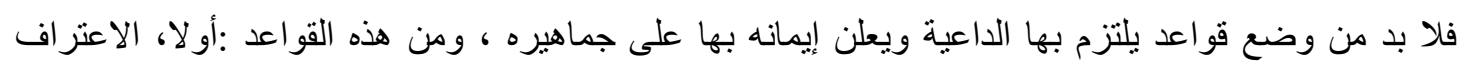

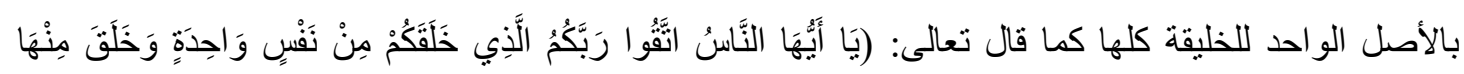

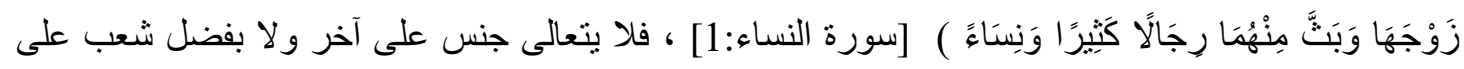

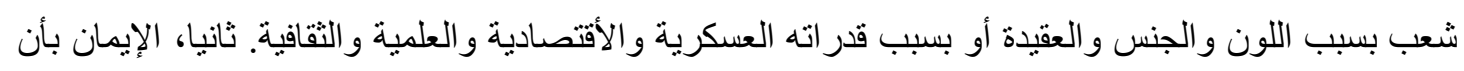

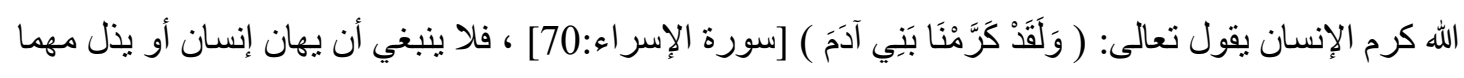

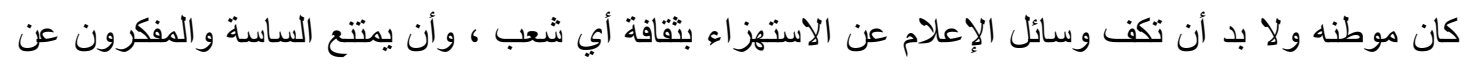
التلميح أو التصريح بدونية ثقافة غير هم أو باستعلاء ثقافتهم على غيرها من ثقافات الأمم. ثالثا، احترام

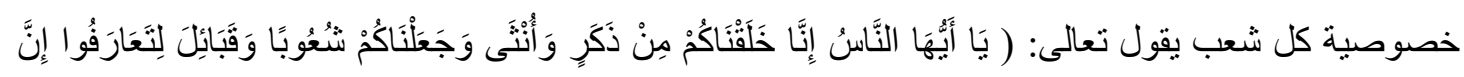

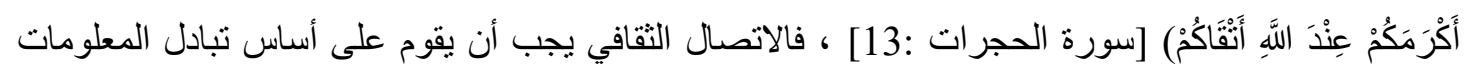

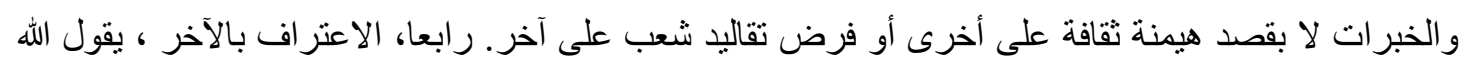

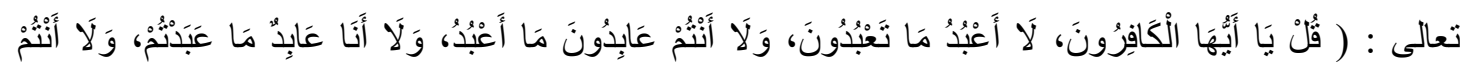

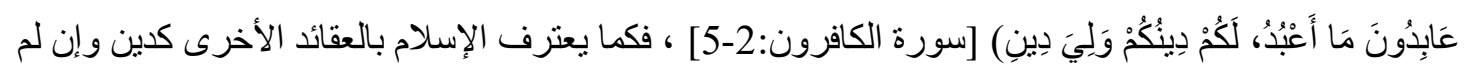
تكن سماوية وتختلف مع الإسلام اختلافا جذريا في العقائد والأحكام فينبغى على الآخرين أن يعترفوا بالإسلام

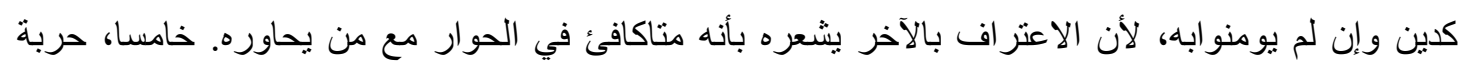

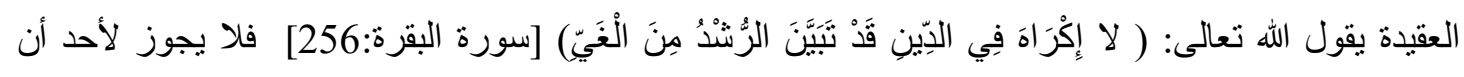

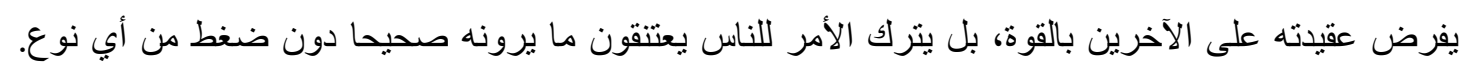

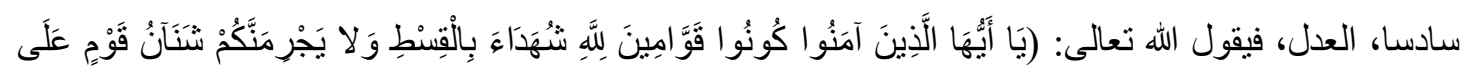

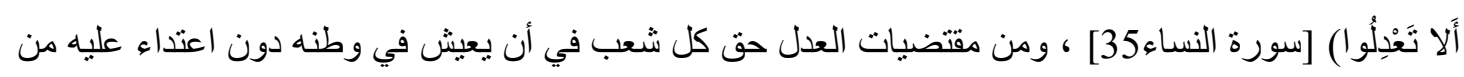

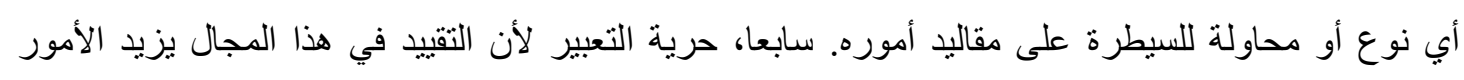

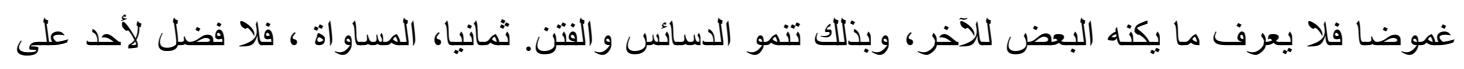


آخر ، وذللك يقتض الاعتراف بحق كل شعب في الموارد الطبيعية في أرضه، فلا استغلال فلا احتكار وإنما تعاون بين الناس على تتمية المو ارد بحيث ينال كل ما يضمن له حياة كريمة تليق بالإنسان الذي كرمه الله.

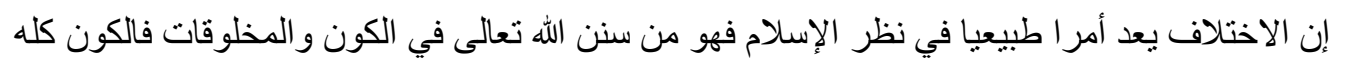

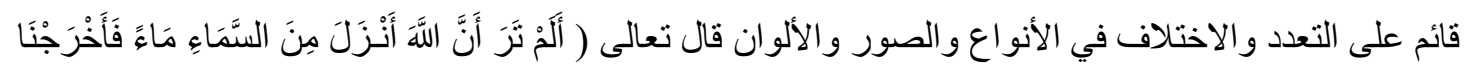

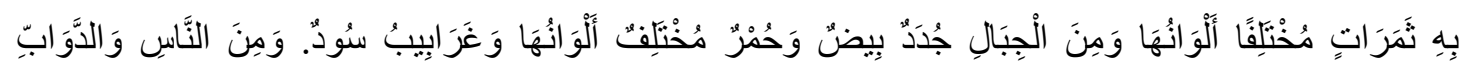

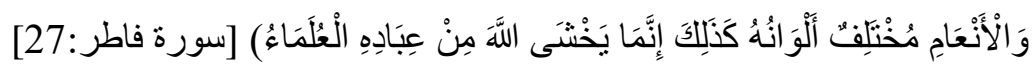
و هكذا فإن هذا الاختلاف هو اختلاف تنوع وتعدد وهو أيضا من آيات الله التى تدل على عظمته وحكمته

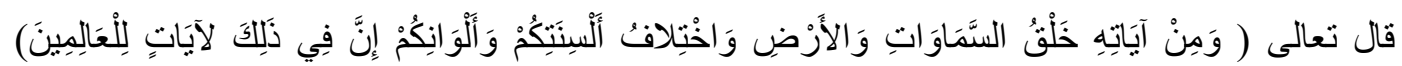

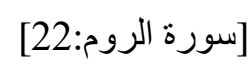
ولقد أقر الإسلام بالإختلاف في الحدود المنطقية والمعقولية ولعل موقف الرسول في في فضية صلاة العصر في بني قريظة لخبر دليل على الإقرار بمشروعية الاختلاف في السنة النبوية ـ كما أن هناك وقائع

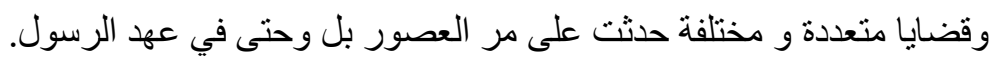

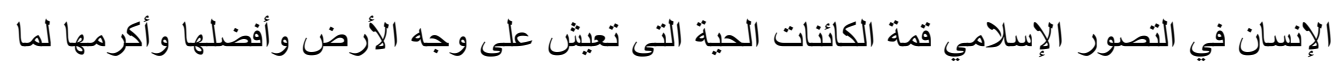

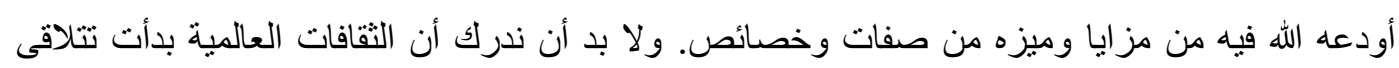

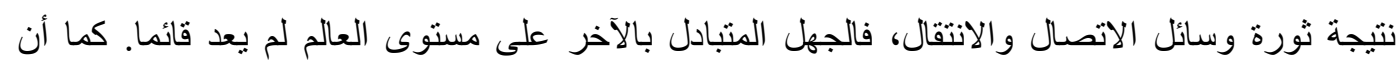
الحواجز بين الثعوب والثقافات سقطت وصار الناس في أجزء مختلفة من العالم يتعرفون على بعضهم فيكتشفون أوجه الاختلاف والاتفاق ـ كذلك هنالك الإحساس المتبادل بين المجتمعات الإنسانية بوجود أخطار مشتركة على العالم كله تتجاوز حدود الثقافات و العقائد الدينية والقوميات مثل العنف في العالم ونفاد الموارد خصوصا المياه وتدمير البيئة نتيجة الإسر اف في التصنيع. كما هو معلوم عند كثير من الناس أن الاختلاف يعد من أبرز خصائص الوجود الإنساني ومن أوكد

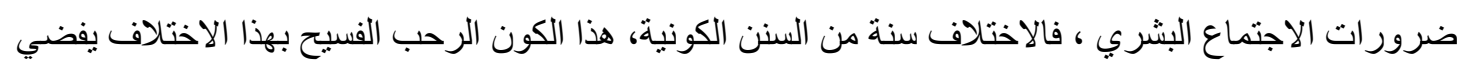

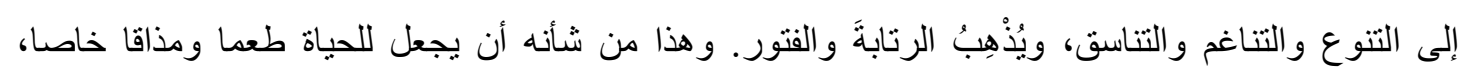

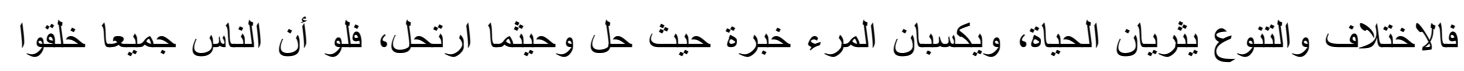
و جبلوا على صورة واحدة، والأماكن كلها كانت على صورة واحدة من حيث طبيعة المكان و المناخ و غير ذلك، ولكان

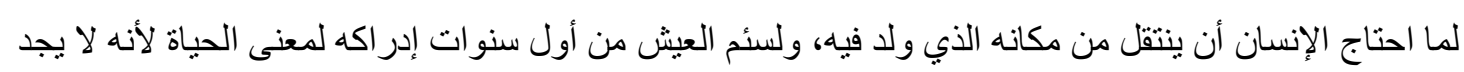
جديدا. ويرى البعض أن أهمية الاختلاف لا تتأتى فقط من كون التنوع هو أصل الاجتماع البشري، بل لأنه أيضا

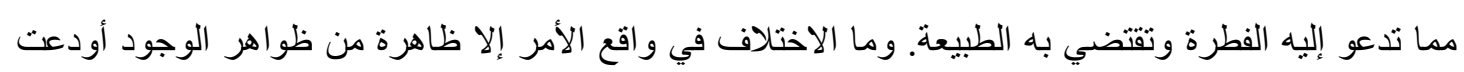

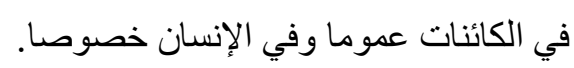
فمن وجهة نظر الإسلام، لو لا سنة الاختلاف التي هي سبب من أسباب الخلق، لاستحالت الحياة. وفي

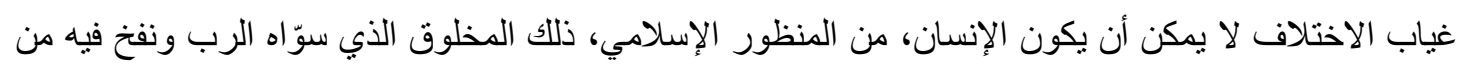

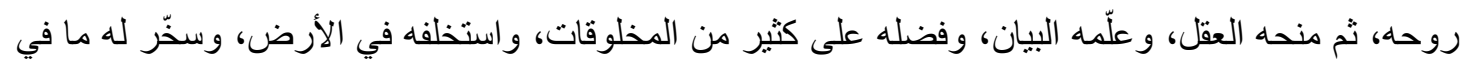

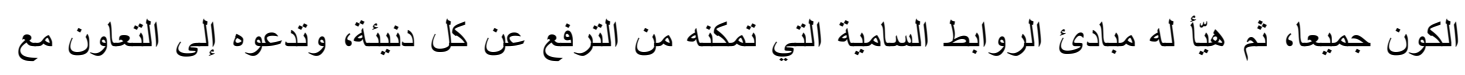


نظيره في الخلق، في عمارة الكون وتدبير المصالح وتبادل المنافع. لقد امتن الله على عباده من خلال كتابه العزيز أن جعل من آياته تعاقب الليل والنهار حتى لا يشعر الإنسان بالملل، ويتسنى لله أن يجعل لكل وقت ما لهائ

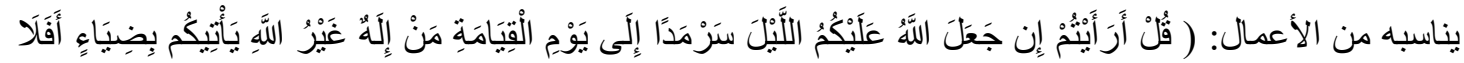

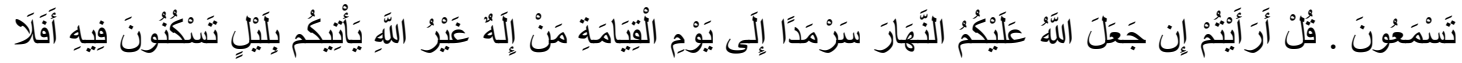

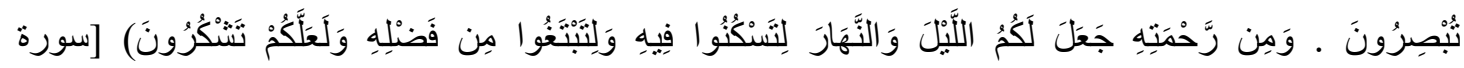

القصص:71-73 ]

انطلاقا من النصوص القرآنية التي حفلت بالآيات الواردة فيها لفظ (الاختلاف) يمكن أن نستتبط بأن

التصور الإسلامي للوجود يرتكز على فكرتين أساسيتين : فكرة وحدانية الخالق وفكرة تعددية الخلق واختلاف المخلوق. و على هذين المحورين دار الإسلام في تصوره وعقيدته وفكرته عن هذا الوجود. فبالنسبة للمسلمين فإن الله وحده هو الواحد، وكل ما بعده متعدد: هو واحد في ذاته وواحد في صفاته وواحد في أفعاله، هو الخالق وحده

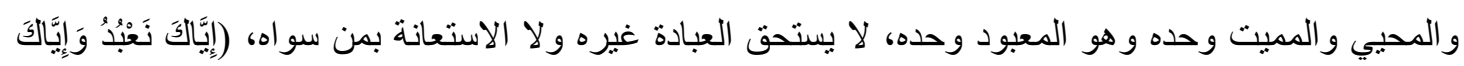

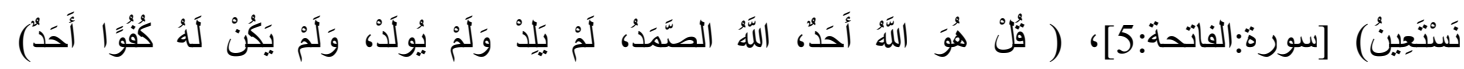
[سورة:الإخلاص: 1-5] و على هذا كان التوحيد في الإسلام بمثابة جوهر هذا الدين و أساسه المتين.

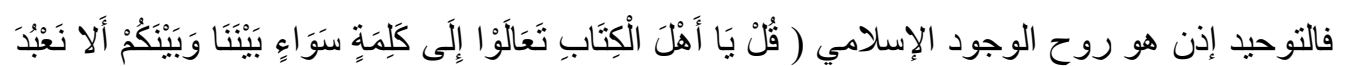

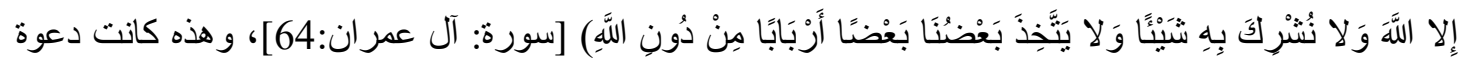

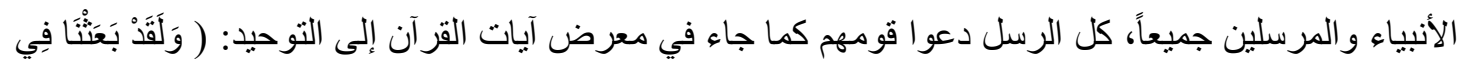

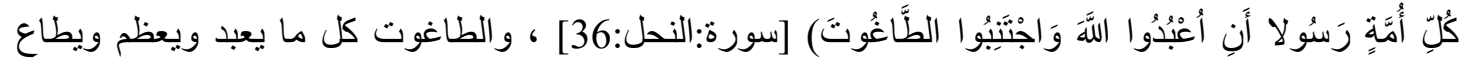
طاعة مطلقة من دون الله سواء كان من البشر أم من غير البشر. فالهدف من بعثة الأنبياء هو تحرير البشرية من

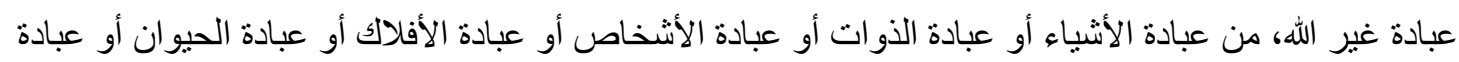
الإنسان أو عبادة الهوى والذات.

تحرير البشر من العبودية لغير الله كان رسالة الأنبياء جميعاً التي تركزت وتجسدت في الدين الخاتم

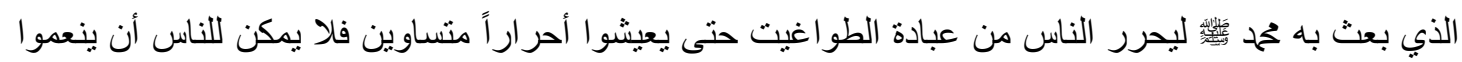

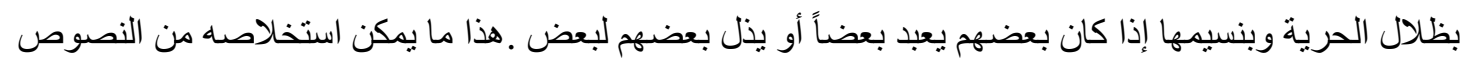

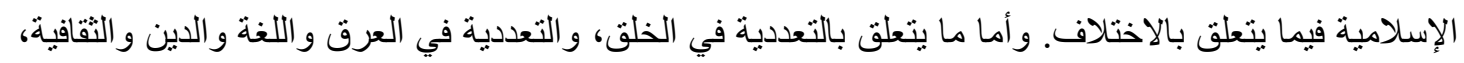
كل هذه التعدديات قد أقرها الإسلام. المسلم ليس وحده في هذا الوجود، هناك آخرون يشاركونه في الحياة. إذن فئن فثمة تعدد في الخلق.

\section{التعددالثقافي في المجتمع}

يعتبر التنوع ظاهرة كونية، فهو يشمل مختلف جو انب الحياة: الإنساني والحيو اني و الطبيعي الجغر افي.

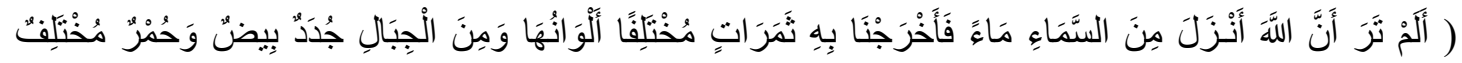

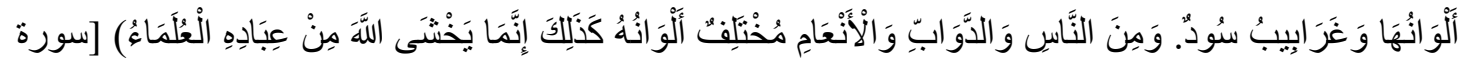

ف27: فاطر

يتضح من خلال هذه الآية القر آنية أن الإنسان كلما كان واعيا بحقيقة الاختلاف، باحثا في الكون مكتشفا

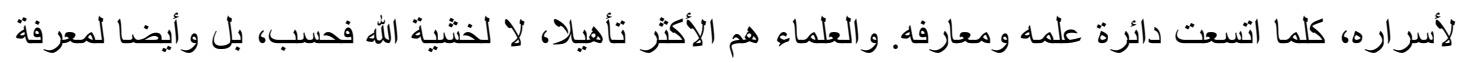


و اكتشاف حقائق الكون وتتو عه، فهم يعرفون بأبحاثهم ومعاينتهم وتجاربهم واكتشافاتهم وخشيتهم لخالقهم أيضا اختلاف الألوان. والتنوع يعبر عنه القرآن باختلاف الألوان، أب اختلاف الأنواع و الأصناف. ثم من شأن هذا الاختلاف الطبيعي الجغر افي والحيو اني و الإنساني أن يثري الحياة الإنسانية على كل أصعدة مستوياتها الاجتماعية والاقتصادية و السياسية والثقافية. بهذا، ومع إقراره بالتعددية العرقية واللسانية و اللغوية، يعترف المنظور الإسلامي كذلك بالتعددية الثقافية. ما دام الناس يتعددون في أعر اقهم ولغاتهم و ألسنتهم

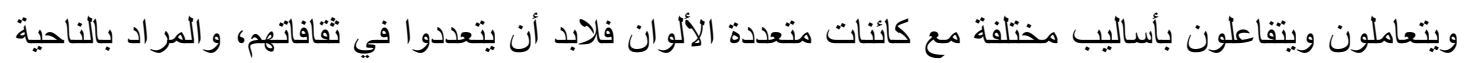

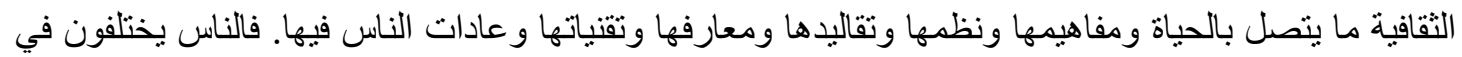
أمور شتى: في ملابسهم ومآكلهم ومشاربهم ومساكنه. لكل جماعة إنسانية طريقةـ وربما طر ائقـ- اتخذتها ومنهج اتبعته في تفاعلها مع محيطها وبيئتها، (لِكُلِّ

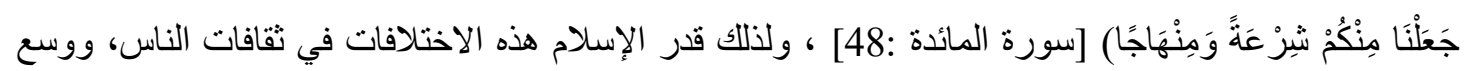
هؤلاء جميعاً. فالناس أحرار في ثنقافاتهم وتقاليدهم و أعر افهر و عاداتهر. ويرى البعض أن الحضارة الإسلامية مثلا، شاركت فيها أنواع عديدة من العناصر والأجناس و الأديان

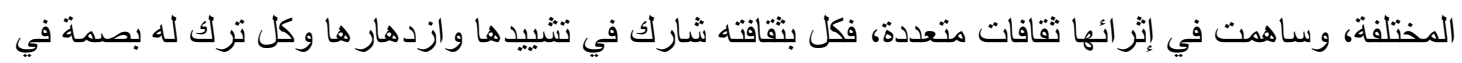
ناحية من النواحي الحياتية فيها.

هذا التعدد في الإسهامات الثقافية من شأنه أن يغني حضارة ما من الحضار ات ويعزز ها وينميها، و على النقيض من ذلك، الحضارة الني تقوم على لون واحد أو شكل واحد أو صورة واحدة فهذه تعد حضارة فقيرة.. الحضارة الغنية هي التي تأخذ وتستفيد من الجميع وتقتبس من الكل. هذا ما يعبر عنه بالتنوع أو التعدد الثقافي

الثري. * التعددية الدينية:

مع هذه التعددية نجد أن هناك في الإسلام تعددية دينية، هذه التعددية الدينية مرتبطة بالتعددية الثقافية ـ

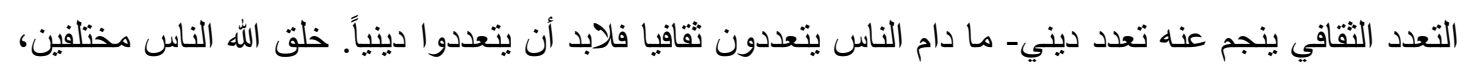
خلق لكل منهم عقلاً يفكر به، ومنحه إر ادة يرجّح بها، ومنحه ملكات وقوى ومواهب دانب مختلفة على أساسها يختار

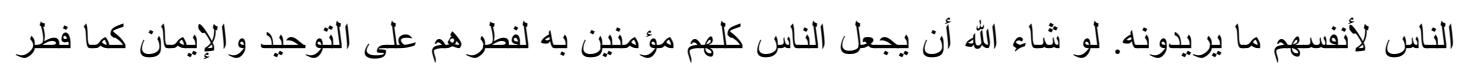

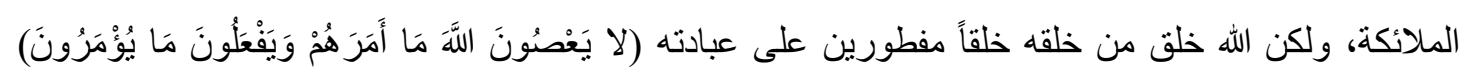

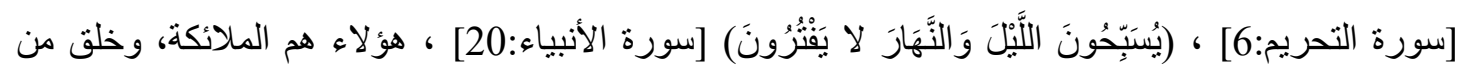

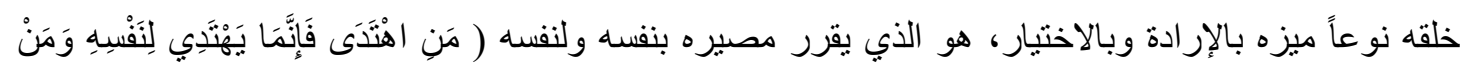

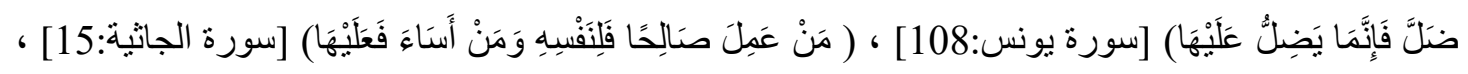

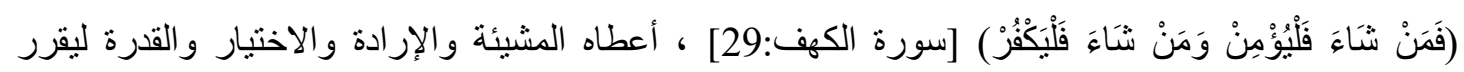
مصيره ويسلك طريقه، هذا النوع هو الإنسان. لم يثأ الله أن يجبره على دين واحد و لا على الإيمان به، بل نرك له الحرية قي هذه القضية، و أعطاه

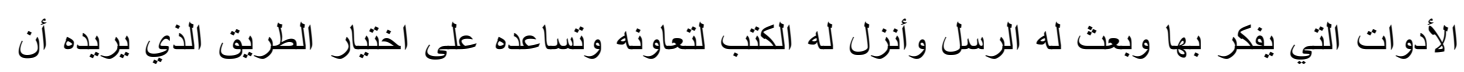

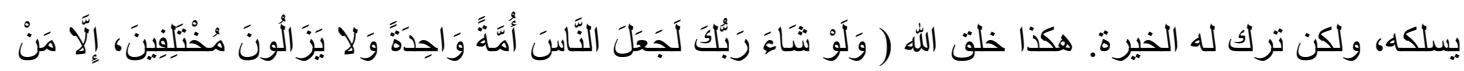

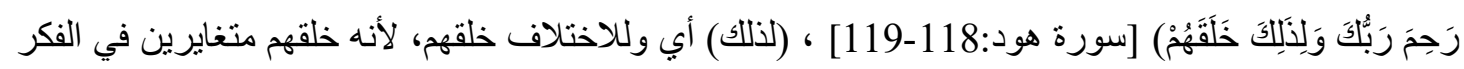

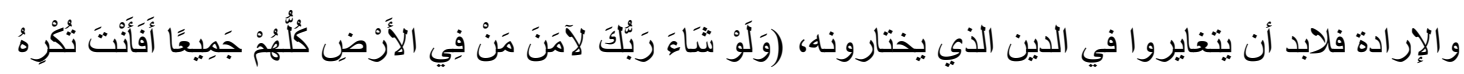

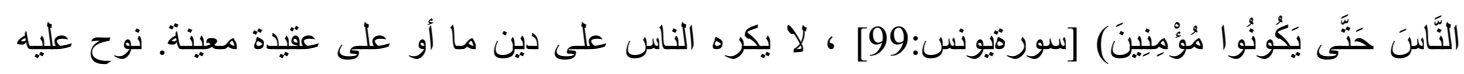




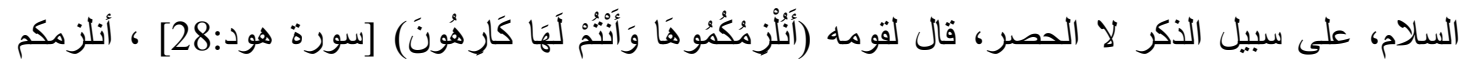

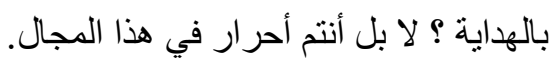

\section{التعدد في الديانة}

قد يظن بعض الناس أنه ليس هناك دين غير الإسلام، لا، بل هناك أديان أخرى، والواقع يؤكد هذا

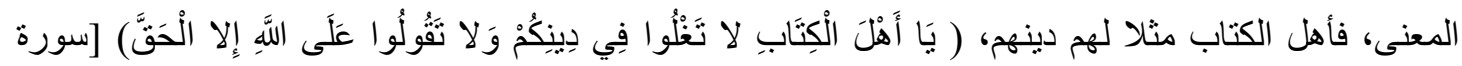
النساء:171] ، هذه الأديان الأخرى وسعها الإسلام، وعاثت في ظلاله قروناً والمسلمون آنذاك بفتوحاتهم

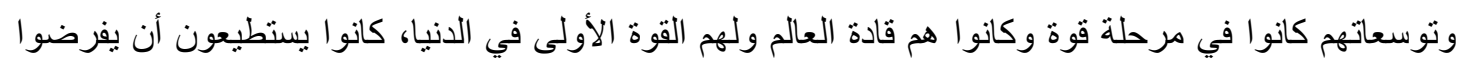

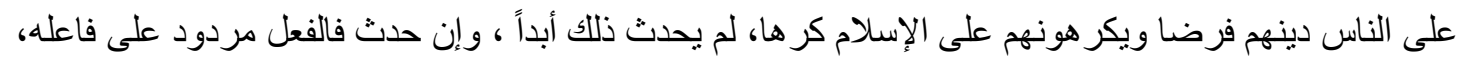
لأن الإسلام لا يقبل إيماناً فيه شبهة إكر اه، لابد للإيمان أن يكون اختبار أ محضاً، ولذلك لم يجبر غير المسلمين في وهي وقت من الأوقات على دخول هذا الدين، وهذا ما قرره بعض المستشرقين الغربيين أنفسهم مثل توماس أرنولد 2 بقوله: "لم يحدث في ناريخ المسلمين أن جماعة أجبرت على أن تدخل في الإسلام إكر اه"، تركوا هؤلاء و عاثشوا

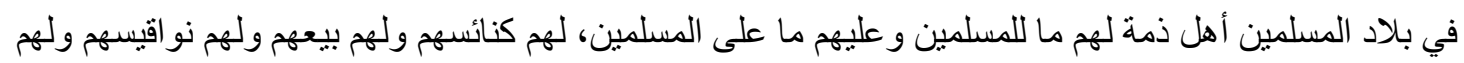
أزياؤهم...، ما أجبر أحد على أن يغير زيه ليكون منل المسلمين، بل بالعكس، ما دام الإسلام قد تركه لدينه

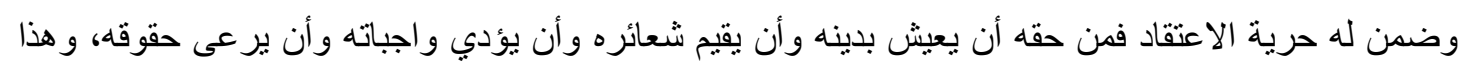
من ثمرات إقرار التعدد واحتر ام مبدأ التسامح. إن التعددية الدينية تحتاج إلى التسامح، وقد يتساءل البعض: كيف يتسامح الإنسان وهو يعتقد أن دينه هو

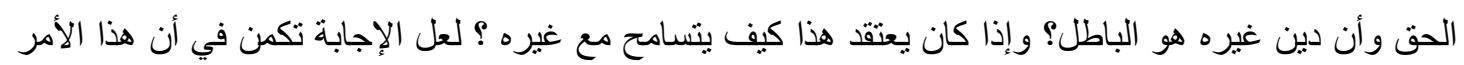

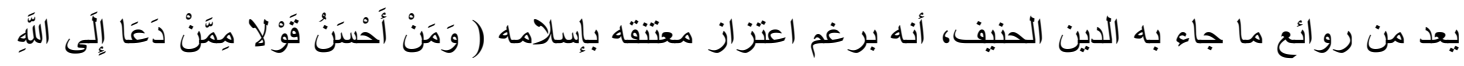

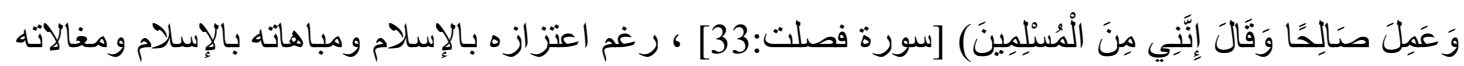

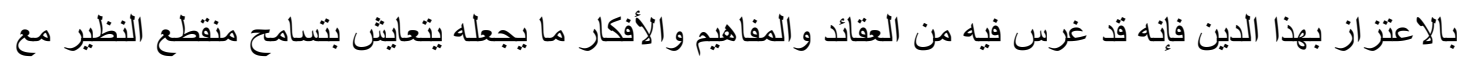

المخالفين له.

من هذه المفاهيم والأفكار الأساسية أنه بين أن اختلاف الناس واقع بمشيئة وإرادة الله الخالق، الله هو

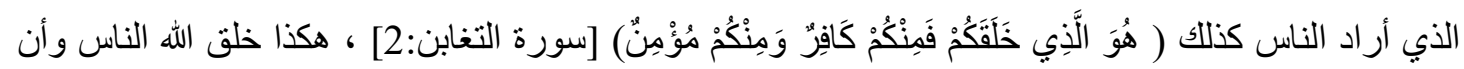

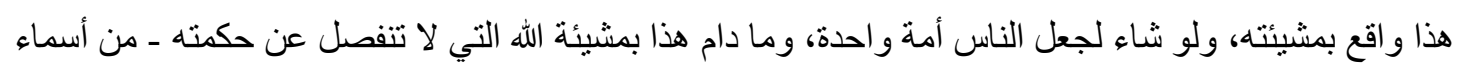
الله وصفاته المذكورة في القرآن: اسم الحكيم ـ فمن العبث أن يقاوم الإنسان مشيئة الله، لأن مشيئة خالقه وبارئه

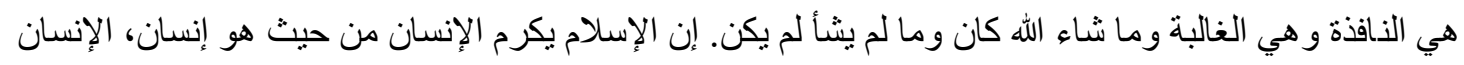

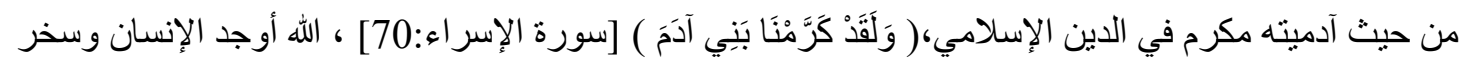

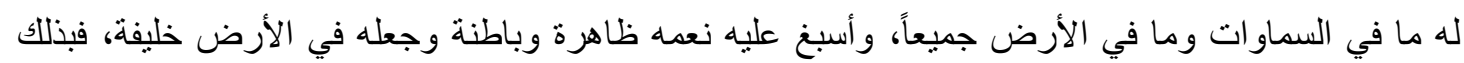

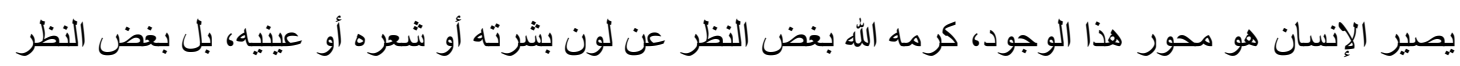

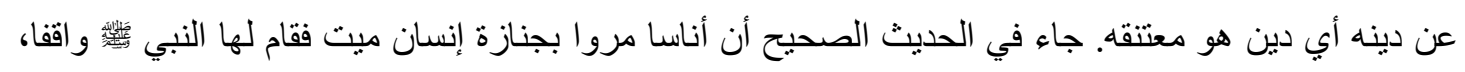

2 توماس آرنولد ، الدعوة إلى الإسلام: بحث في تاريخ نشر العقيدة الإسلامية، نقله إلى العربية د. حسن إبراهيم حسن 
فقالوا: يا رسول الله إنها جنازة يهودي، هل تقوم احتراماً لها؟ فقال النبي

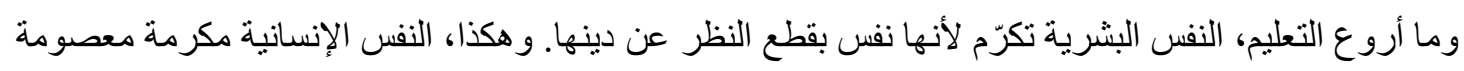

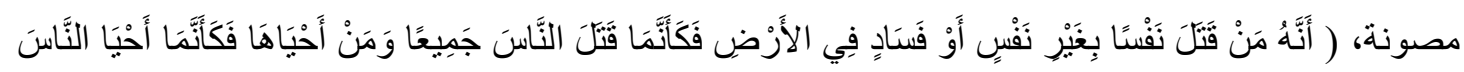
جَمِيعًا) [سورة المائدة:32] هذا هو الأمر الثاني الذي يعالج به الإسلام التعصب ويسعى لمحوه من نفسية الفرد

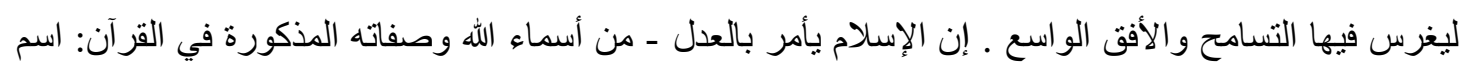

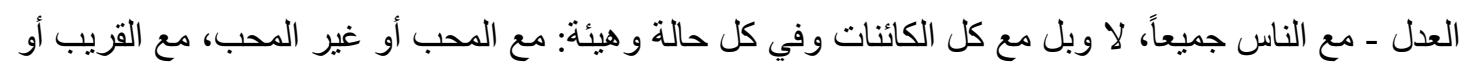
البعيد، مع الصديق أو العدو، مع المسالم أو المحارب، مع المسلم أو غير المسلم، فالعدل للناس جميعاً بدون

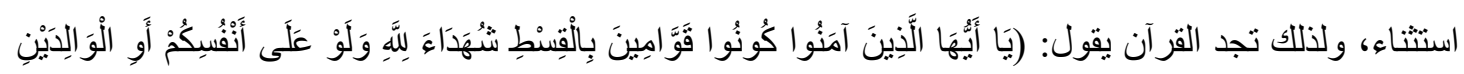
وَالأَفرَبِينَ) [سورة النساء:135 ، هذا عدل مع المحب أو القريب، ويقول في آية أخرى في شأن البغيض أو البعيد

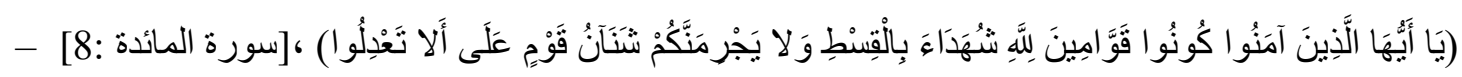

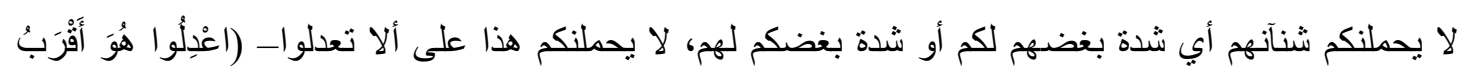

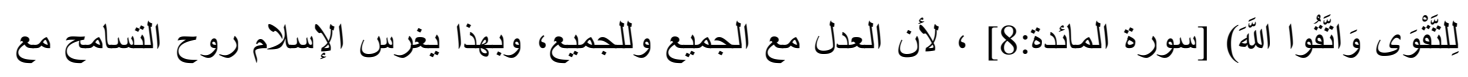

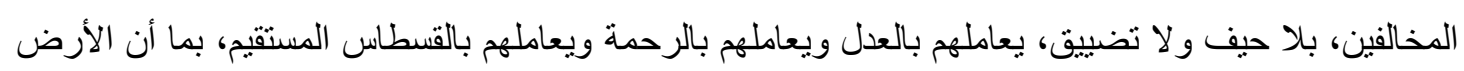

تسع الجميع.

\section{الوسطية الإسلامية تعلى قيمة التسامح :}

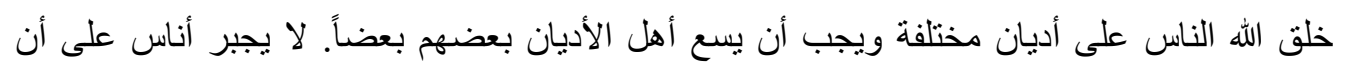

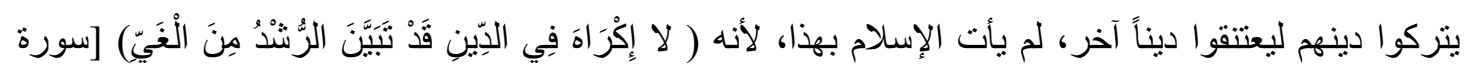

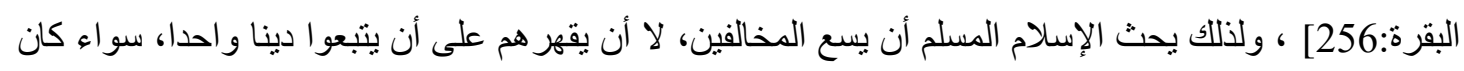

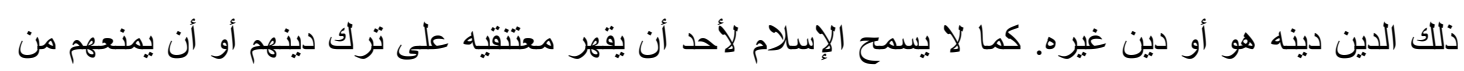

طاعة ربهر. هذه التعددية الدينية هي التي قرر ها الإسلام منذ العهد المكي وفي العهد المدني أبضا.

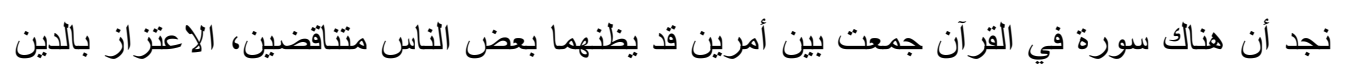
إلى أقصى حد والتسامح مع المخالف إلى أقصى حد، هذه السورة هي سورة الكافرون. السورة الوحيدة التي

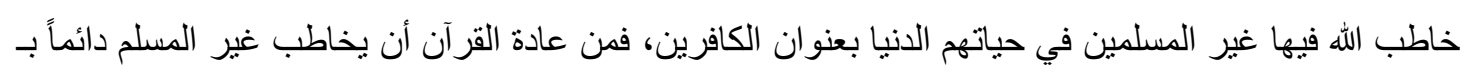

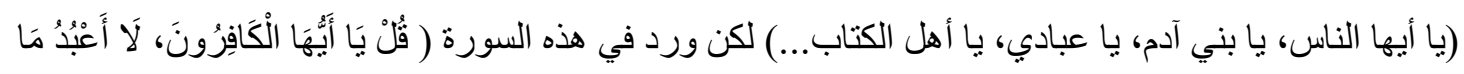

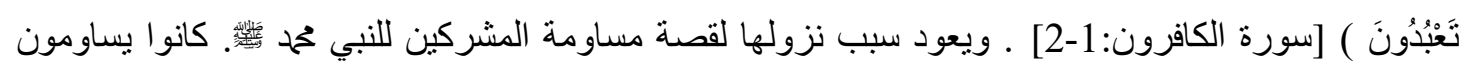

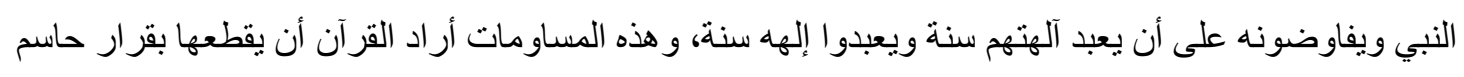

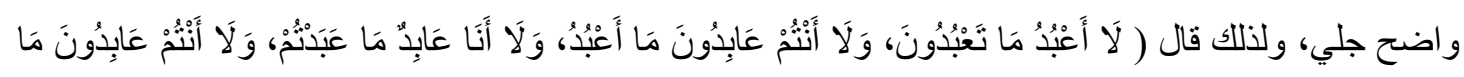

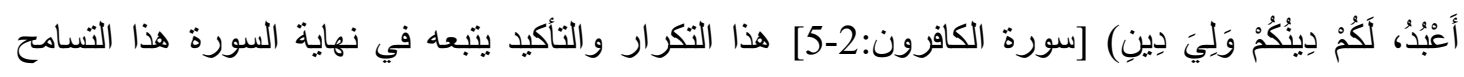

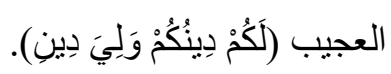

و لا يخفى على باحث أن ابتعاث رسول الله كان منعطفا تاريخيا في حياة الناس جميعا وتحولا حضاريا متمييزا في نهج حياتهم وتعاملهم. تحول الخطاب فيه من قومية الأديان ومحدودية مقاصدها إلى عالمية 
الإسلام وشمولية دعوته وتكامل مقاصده ومن عزلة المجمعات البشرية وتضادها وتصار عها إلى وحدة الأسرة البشرية وتعاون مجتمعاتها. حيث سمع الناس لأول مرة في تاريخهم الإنساني فكرة المجتمع الإنساني

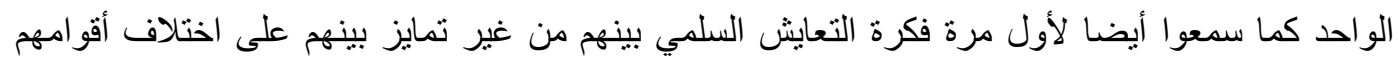
و أجناسهم و أعر اقهم وأديانهم وأوطانهم. و وكان النبي يعمل على نشر الإخاء الإنساني الذي يتجاوز المسلمين

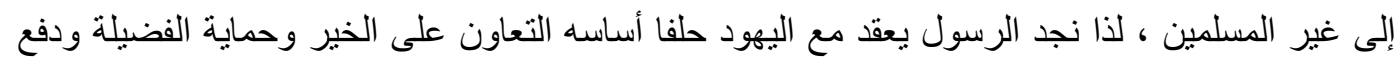
الأذى وحماية المدينة من كل اعتداء ومنع الظلم وردع المجرمين العابثين بالأمن و أكد النبي ذلك بلكئل بالمو اثثيق.

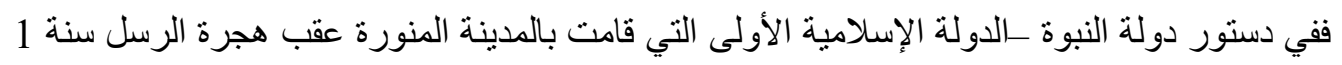
هـ - 622 م نجد مواد هذا الدستور الذي اشتهر في مصادر التاريخ الإسلامي بالصحيفة والكتاب. نجد مواد

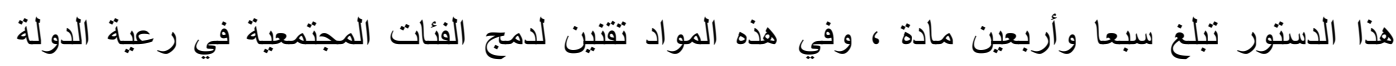
و اعتبار هم أمة مع المؤمنين- المهاجرين والأنصار - وتقنين المساواة بينهم وبين المؤمنين في الحقوق و الواجبات مع تقنين حقهم الكامل في الاعتقاد الديني الذي يختلفون فيه مع الإسلام و المسلمين ـ ونقرأ في هذه ونه المواد الدستورية أرقى صور التقنين للاعتر اف بالآخر ومساواة الأقلية للأغلبية وتقرير التعددية الدينية في رعية الدولة الواحدة.5 - مئ.

نص هذا الدستور على أن اليهود أمة مع المؤمنين لليهود دينهم وللمسلين دينهم ومن تبعنا من يهود فإن لهم النصر والأسوة غير مظلومين ولا متناصر عليهم وأن بطانة اليهود ومواليهم كأنفسهم. وأن اليهود ينفقون مع المؤمنين

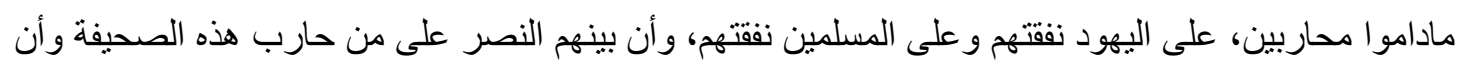
بينهم النصح والنصيحة والبر المحصن من أهل هذه الصحيفة دون الإثم لا يكسب كاسب إلا على نفسه

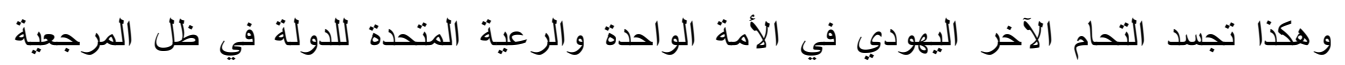
الإسلامية ومن خلال سعتها التى نص عليها هذا الدستور عندما قال : و إنه ماكان من أهل هذه الصحيفة من حدث الأه

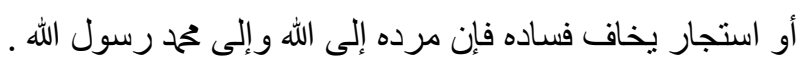

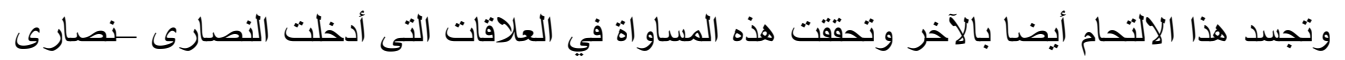
نجر ان- وكل المتدينين بالنصر انية في صلب الأمة الواحدة. فنص ميثاق العهد الذى كتبه الرسول لنصارى نجر ان

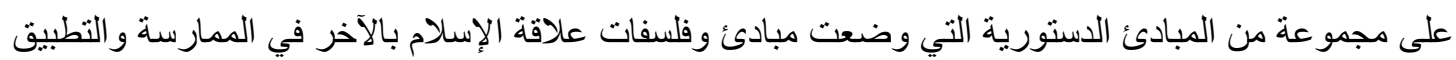

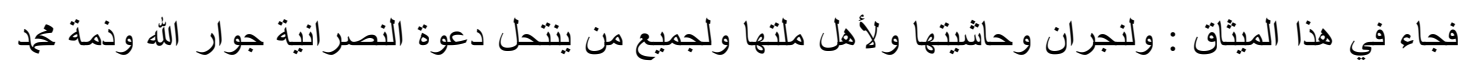

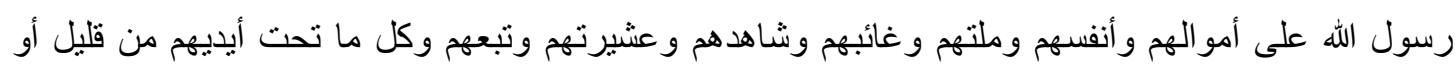

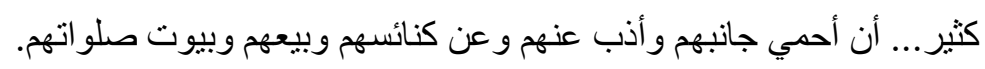
و اهتماما من الإسلام في توفير عو امل التلاحم للأمة الواحدة التى جعل الإسلام وحدتها فريضة نص ولئه عليها القر آن

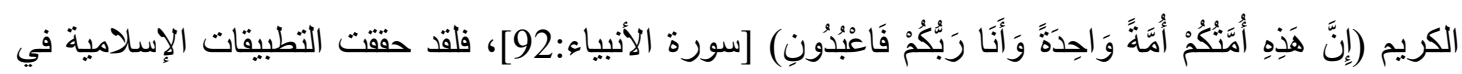

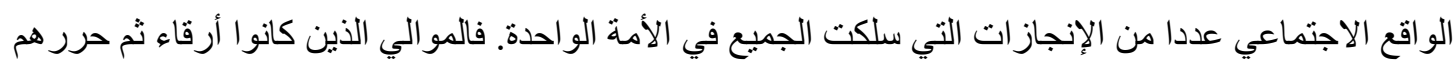

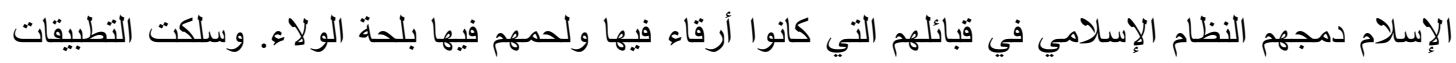

$$
4 \text { الإسلام و المسيحية، إيليكس جور افسكي ، ص } 18 \text { عالم المعرفة الكويت 1996،. }
$$
5 مجموعة الوثائق السياسية للعهد النبوي والخلافة الر اثدة، ححم حميد الله الحيدر آبادي، 17-21 طبعة القاهرة سنة 1956. 
الإسلامية باب المصاهرة والزواج بين المسلمين وبين الكتابيات المحصنات لتحقيق أعلى درجات التلاحم بين غير المسلمين وبين المسلمين في بناء الأمة الواحدة. و الإسلام لا يكتفي بمحو أسباب التفرق والنزاع بين الناس بل يدعو إلى التسامح العام لأن التسامح يداوى القلوب المكلومة ويجتذب النفوس النافرة. فالإسلام منهج الناس جميعا ومقاصده لخيرهم وفلاحهم وخطابه لهم على اختلاف أقوامهم وأجناسهم وأديانهم. فهو تحول حضاري شامل ينتقل بالناس من ضيق القوميات والأعراق والأجناس إلى سعة الأسرة البشرية وتعاوم مجتعاتها في إطار منهجية الممجتمع ولهم الإنساني الواحد وفي إطار منهج التعاون بين الناس جميعا على أساس من قيم ربهر. ومما لا يخفى أن الإسلام قدم نظرة شاملة ورؤية متكاملة للكون و الحياة و الإنسان و أن هذه النظرة تبقى لئى أساسية وصالحة للبشر في كل زمان ومكان. و هذه الرؤية تشمل الأخلاق والسياسة و الاقتصاد و الاجتماع، ومن هذه المنطلقات قامت الحضارة الإسلامية على مبدأين مهمين و التغيير والاستشر اف. ومما يدل على وهلى ذللك ما جاء في فو اتح كتب الرسول إلى إمبراطور الروم وكسرى. فقد جاء في رسائل الرسول بعد المقدمة (

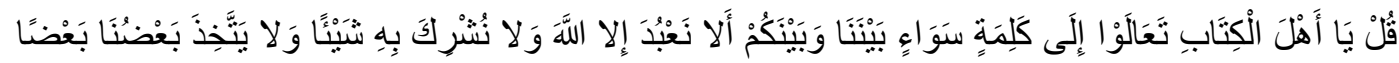

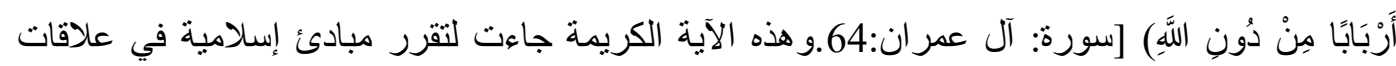
المسلمين مع كل الناس. وهي مبدأ الاعتراف بالآخرين، مبدأ الحوار وأهميته، مبدأ احترام المشيئة الذاتية لدى الآخر، مبدأ استشر اف المستقبل في طل علاقات إنسانية سامية.

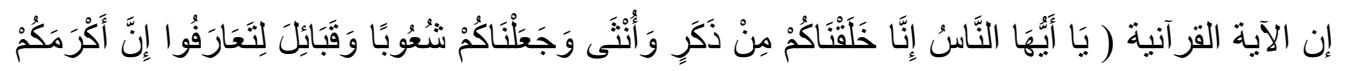

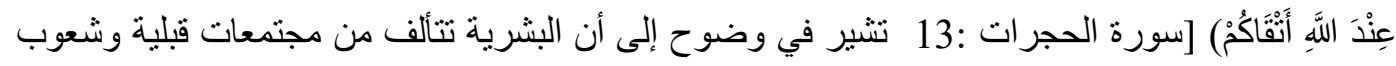
أو أقو ام. وكلمة الناس هي تعبير عن الجنس العام يشملها جميعا. وتثير الأية أيضا إلى اتجاه تطور البشرية، أسر أو قبائل وشعوب في اتجاه التعارف وهو المعرفة المتبادلة من جميع الأطر اف.

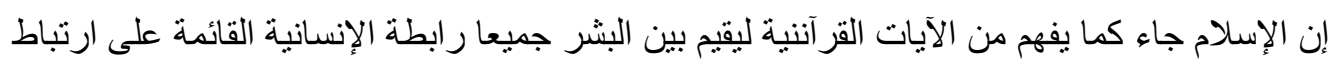
البشر جميعا بالله الخالق فهم جميعا عباد الله. لقد جعل الله اختلاف الناس شعوبا وقبائل للتعارف و التعاون لا للتباغض و التنازع. فاختلاف الثتعوب له له غاية أرادها الله عز وجل، وهو التعارف و هذا التعارف له ظواهر منها اللقاء على مودة وتراحم في أمن

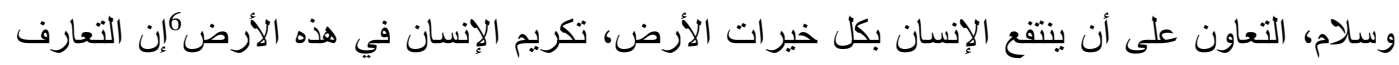
يقود إلى التعاون البناء المستمر الذي يفيد الإنسانية جمعاء. إن منهج القرآن يعلم المسلين أن البشرية مدعوة الإندان

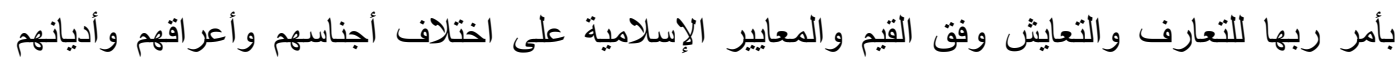

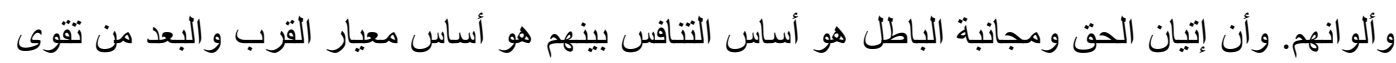

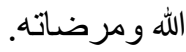
ومن سماحة الإسلام ومرونته في التعامل مع التعددية في المجتمع أن يضمن أمن الفرد غير المسلم ولو

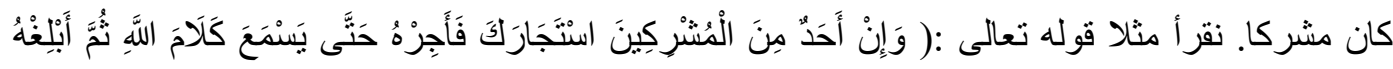

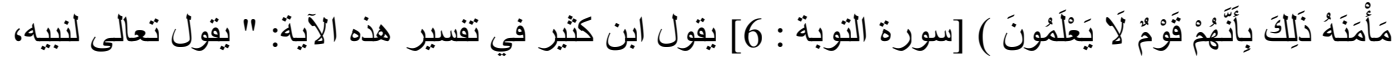


صلوات الله وسلامه عليه: ( وَإِنْ أَحَدُّ مِنَ الْمُشْرِكِينَ) الذين أمرتلك بقتالهم، وأحلات للك استباحة نفوسهر

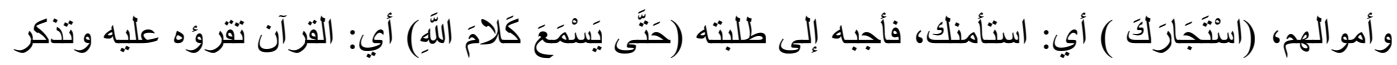

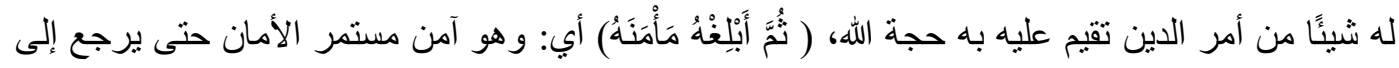

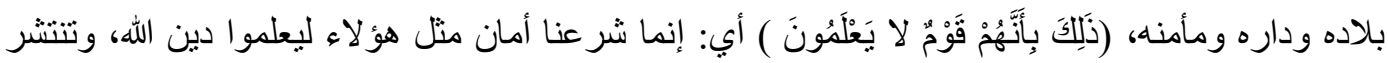

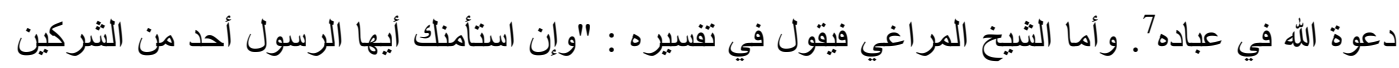
لكي يسمع كلام الله تعالى ويعلم حقيقة ما تدعو إليه أو ليلقاك-و إن لم يذكر سببا- فأجره و أمنه على نفسه

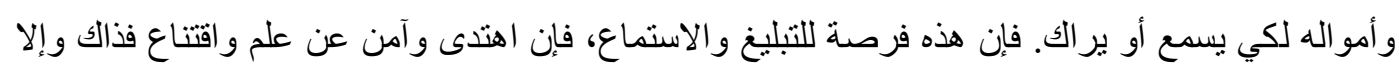
فالو اجب أن تبلغه المكان الذي يأمن فيه على نفسه ويكون حرا في عقيدته حيث لا يكون للمسلمين سلطان

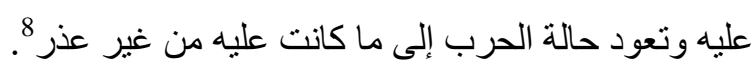

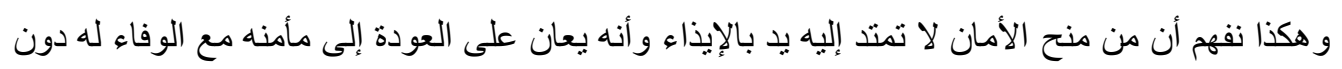
غدر به أو خيانه له.

وفي الحديث النبوي نجد ما يكثف أن سماحة الإسلام مع مخالفيه و أعدائه وسموه في التعامل معهم بلغ حدا يتحدى به البشرية بأسر ها أن تجد له نظيرا في غير الإسلام. لقد أظهر هذا الحديث بشاعة الغدر بمن منح له له

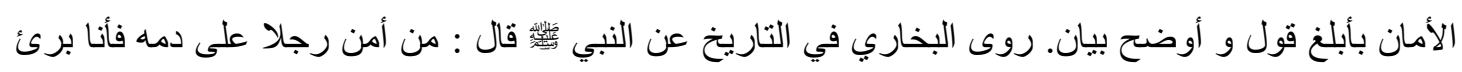

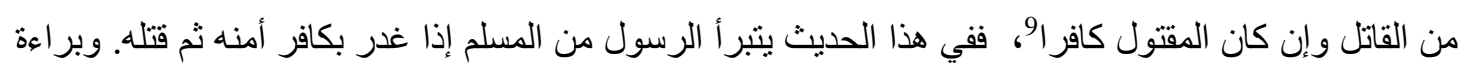
الرسول من مسلم تعني خسر انه الدنيا والآخرة.

ومن أكبر نماذج التسامح والاعتر اف بالتعددية في الحضارة الإسلامية ما نقرأ في الوثيقة العمرية في

فتح بيت المقدس سنة 15 هـ أي بعد وفاة النبي بخمسة أعوام. و هذه الوثيقة لها مكانة كبرى في الحضارة الإسلامية و أنها دالة على مدى تسامح الفتوحات الإسلامية والفاتحين المسلمين. وهذا نص الوثيقة التى تكاد تجمع عليه المصادر التناريخية:

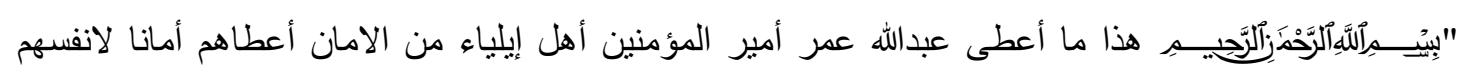

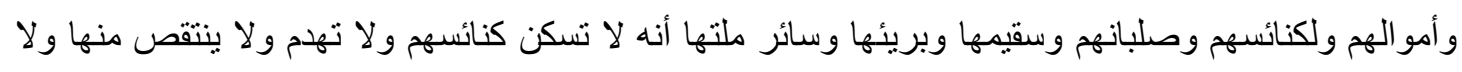
من حيز ها و لا من صليبهح و لا من شئ من أمو الهم ولا يكر هون على دينهم و لا يضار أحد منهم و لا يسكن بايليلياء

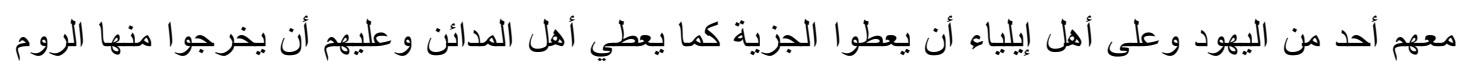

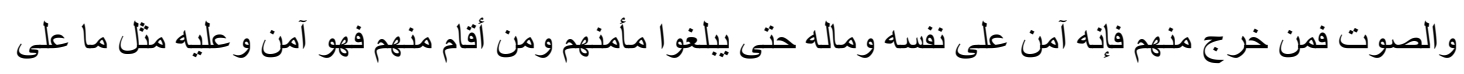
أهل إيلياء من الجزية ومن أحب من أهل إلياء أن يسير بنفسه وماله مع الروم ويخلى بيعهم وصلبهم فإنهم آمنون

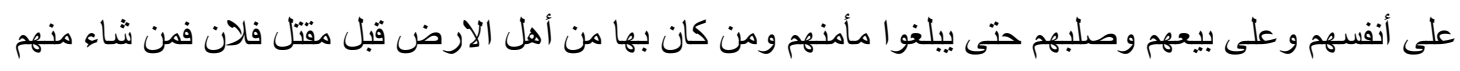
قعد و عليه منل ما على أهل إيلياء من الجزية ومن شاء سار مع الروم ومن شاء رجع إلى أهله فإنه لا يؤخذ منهم شئ حتى يحصد حصادهم و على ما في هذا الكتاب عهر الله وذمة رسوله وذمة الخلفاء وذمة المؤمنين إذا أعطوا 
الذي عليهه من الجزية شهد على ذلك خالد بن الوليد وعمرو بن العاصى و عبد الرحمن بن عوف ومعاوية بن أبي سفيان وكتب وحضر سنة خمسة عشر"

التعدد الثقافي في المجتمع الإندونيسي :

أغلبية الشعب الإندونيسي من المسلمين، يمثلون العدد الأكبر للمسلمين في أي بلد في العالم إذ يصل عددهم 205 ملايين نسمة من أصل 230 مليون نسمة هم تعداد إندونيسيا، لكنهم يضربون مثلا يحترم، ويحتذى،

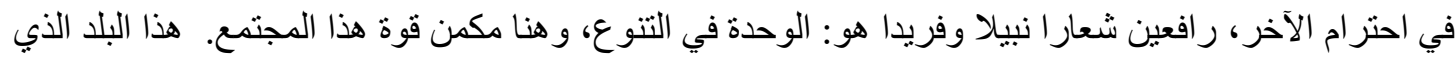
يضم أكبر تجمع سكاني من المسلمين في أرجاء العالم يعيشون في 17 ألف جزيرة تجسد جغر افية المكان. ستة آلاف منها فقط مأهولة بالسكان، ويتكلمون 262 لغة محلية، ويتنو عون في 240 جماعة عرقية، ويشكلون 230 مليونا يتوز عون شرقاو غربا في بلد تقطع الطائرة المسافة بين أقصى شرقه إلى أقصى غربه في ثماني ساعات. التحضر. يقدم كل قطر من إندونيسا نقافات متنوعة إندونيسيا، حيث يكثر بناء البيوت الخشبية في أرجاء إندونيسيا، إضافة إلى المساجد والمعابد البوذية، و الكونفوشوية، و التي كانت ممنوعة من البناء في عهذ سوهارتو ، وسمح الرئيس الإندونيسي الحالي سو سيلو بامبانج يودويونو بإعادة بناء هذه المعابد، تأكيدا على حرية العبادة المتاحة لكل أهل إندونيسيا أيا كانت دياناتهم. والكل يعبر عن الثقافة والتقاليد التي تخص السكان ولبيان البون الثاسع في ثقافات هذا البلا يمكن عقد مقارنة واحدة للتمثيل فقط على مدى التنوع، والاختلاف بين أهل جاكارتا نفسها كسكان عاصمة مدنيين، تبدو عليهم مظاهر العولمة في أزيائهم العصرية، ويركبون السيار ات أو الدراجات البخارية، بينما أهل جزيرة بابوا في شمال شرق إندونيسيا يتسمون ببشرة سمراء ويلونون وجوههم وأجسادهم العارية، بألوان ورسوم عديدة، ويعتمرون قلنسوات من ريش الطيور، ويستخدمون الحراب في شكل يذكرنا بسكان الجزر القدامى، أو سكان أمريكا الأصليين، وبالبدائية التي كانت نمطا للحياة لدى العديد من الثعوب قبل فيل آلاف السنوات. و لايز الون يعيشون هذه الحياة البدائية القائمة على الصيد حتى اليوم.هنا تقدم إندونيسيا نموذجا

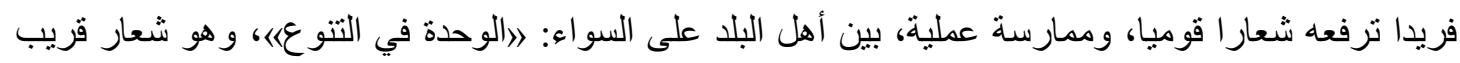
الثبه من العديد من سكان آسيا، الذين يميلون لصيغ التعايش والتعاطي مع الآخر واحترامه أيا كانت ديانته أو ثقافته الأصلية أو معتقداته.

الوحدة في التنوع لا ييدو مجرد شعار بقدر ما يبدو ثقافة حياة، فصحيح أن هنالك مئات المساجد في

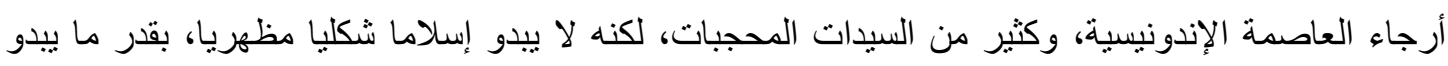
كثقافة تستخلص روح العقيدة الإسلامية بلا نزوع للكثير من الثكليات، وفي جوهر هذا التمثل للعقيدة احترام

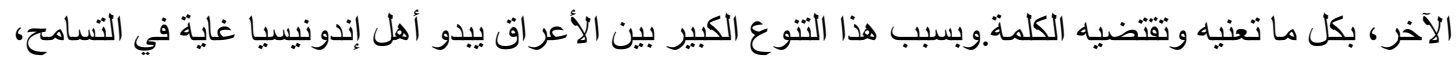
وتكتسب ملامحهم لونا من الهدوء. بمعنى آخر تقدم إندونيسيا نموذجا للتعايش، لا تسود به ثقافة الزحام مما نرى في بعض العو اصم التي ينسبب فيها الزحام ممنلة في الصخب و الضجيج و العشو ائي. بالر غم من دخول الإسلام لإندونيسيا قبل عدة قرون، فإنهم لا يز الون يحافظون على طقوسهم الاحتفالية الخاصة، فشهدنا مثلا مسيرة كرنفالية، حيث يقوم عدد من الثباب الذين برتدون أقنعة مستمدة من ثقافاتهم 
القديمة، يعزفون موسيقى صاخبة بينما يحملون ما يشبه عرشا صغير ا من الخشب يتوسطه صبي صغير يرتدي

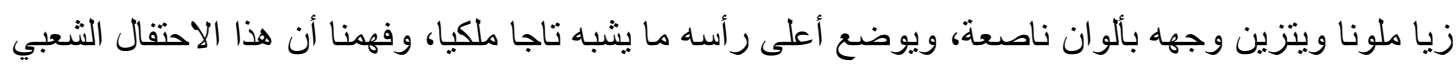

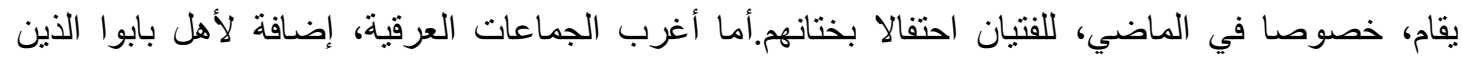
لايز الون يعيشون حياة بدائية تشبه حياتهم قبل وصول المستعمر الهولندي إلى جزر إندونيسيا ولا يزالون

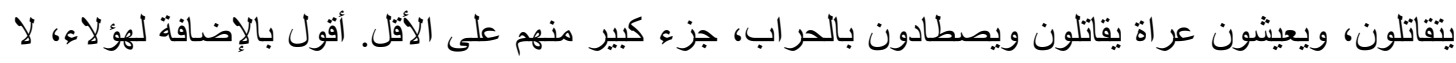

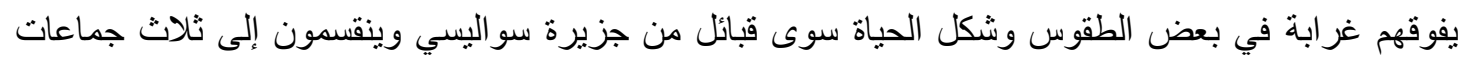
هي: بوجينيز، ماكاساريس، ونور اجا، و هؤلاء لهم طقوس مختلفة في دفن موتاهم، تتمثل في دفنهم في غرف

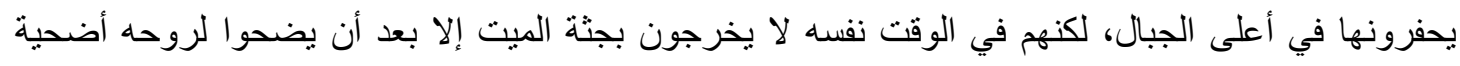

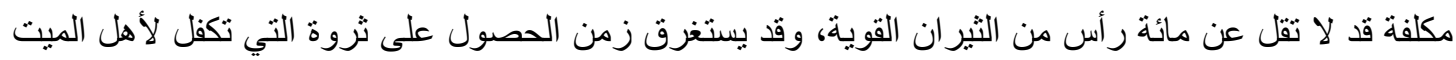

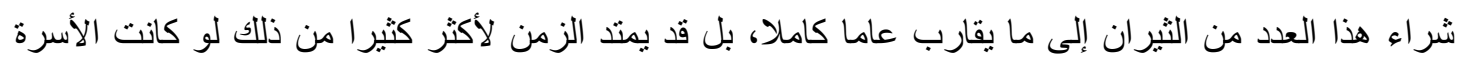
فقيرة، يحتفظ خلالها بالميت في بيته، حتى لو تحولت جثثه إلى رفات.

\section{امتزاج الثقافة والدين}

إن دخول الإسلام إلى إندونيسيا واعتناق أغلبية سكان البلاد للادين الإسلامي وانتشار الثقافة الإسلامية، و المساجد، والمر اكز الإسلامية، والجامعات الإسلامية، وانتشار الدروس الدينية في المساجد للرجال و السيدات، لم يمنع حفاظ أهل إندونيسيا على ثقافاتهم القديمة و عاداتهم، بل و الكثير من طقوس الاحتفالات الخاصة بمناسبات اجتماعية وتربوية عدة، بل ويمزجون بعض طقوسهم القديمة في احتفالاتهم الدينية. وحتى في كل المساجد التي

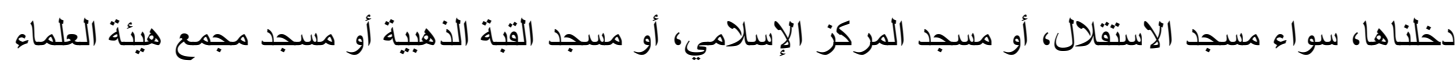
و غير ها، كان هناك دائما طبل ضخم يستقر في أحد أركان المسجد. وقد كانت هذه الطبول تستخدم للنداء للصداة

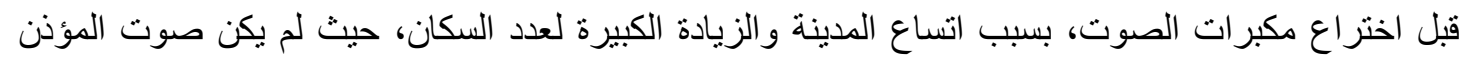

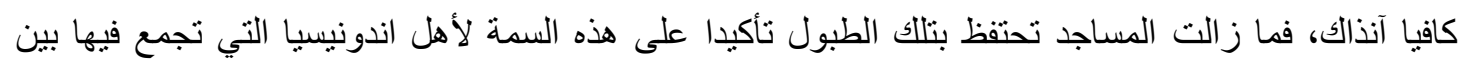

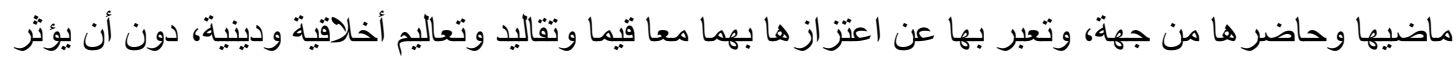
ذللك على العبادات بطبيعة الحال. وتعبر هذه الطبول (تعرف باسم Bedug) عن البيئة، من جهة أخرى، كون جسمها الخشبي يصنع من إحدى الأشجار العملاقة التي تنتشر في إندونيسيا وهي شجرة قد يصل قطر جذعها إلى بـى مثر ونصف أو أكثر. وتعرف باسم شجرة مور انتي نويصل عمر الواحدة منها يتجاوز 300 عام. وهناك العديد

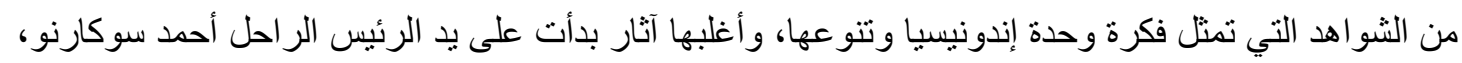

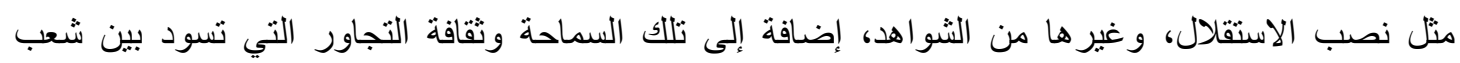

تثير المصادر إلى أن اسم إندونيسيا قد اشتق من الكلمنين اللاتينية إندوس Indus، والإغريقية 》نيسوس《Nesos ، بمعنى جزر الإندوس. وتشير الدراسات إلى أن الجماعات الني عاثت في هذه المنطقة

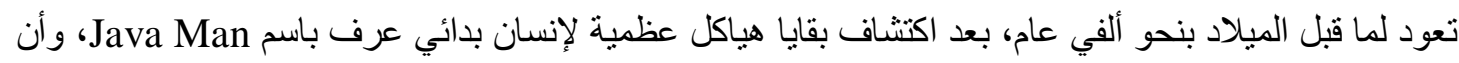

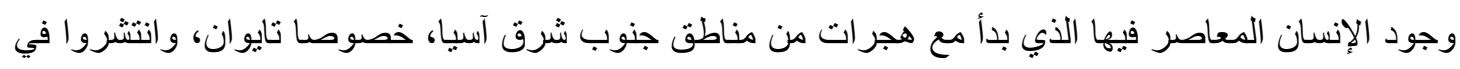
هذه المنطقة وماليزيا و عملوا في زراعة الأرز بسبب خصوبة التربة. أما دخول الإسلام إلى إندونيسيا فيعود

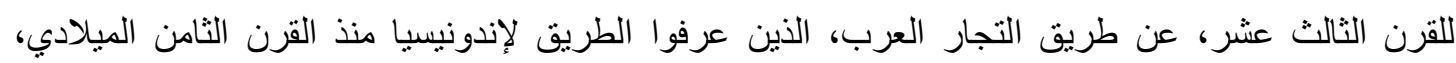


و واستقر الكثيرون منهم في إندونيسيا، خصوصا أهل اليمن، والذين عرفوا بالحضارمة، واليوم تجد الكثبر من أهل

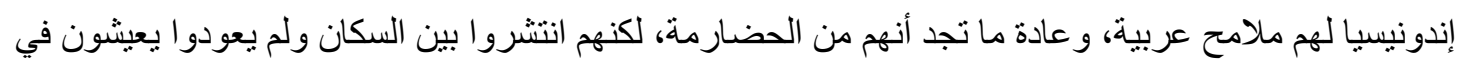

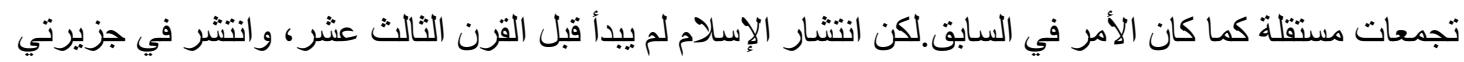
سومطرة وجاوا أولا ثم انتقل إلى بقية أرجاء إندونيسيا لاحقا، باستثناء بالي التي ظلت محافظة على ديانتها الهندوسية حتى القرن السادس عشر .و انتشر الإسلام في ربوع إندونيسيا في هدوء وسلام، ربما بسبب طبيعة أهل

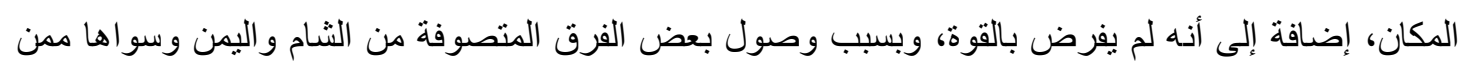

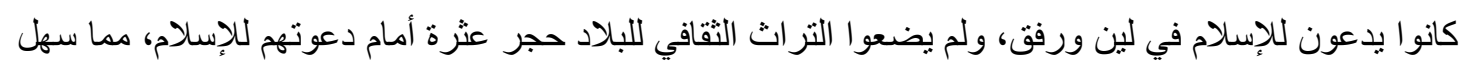

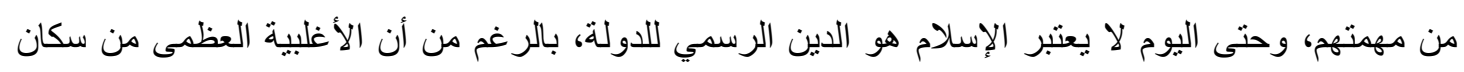

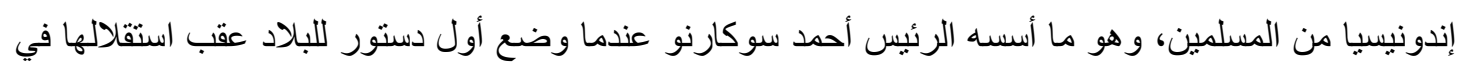
العام 1945، وماز ال معمو لا به حتى اليوم، ما يجعل من التجربة الإسلامية الإندونيسية تجربة تستحق التأمل.

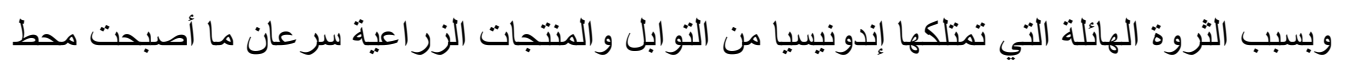

أنظار الدول الاستعمارية، بدءا من البرتغاليين الذين وصلوها لأول مرة عام 1512 حين وصلت سفينة تحمل

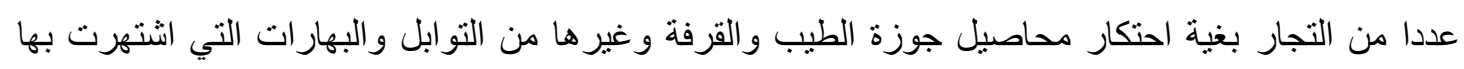

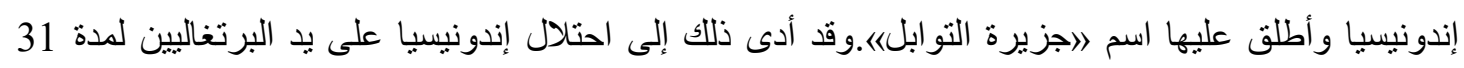

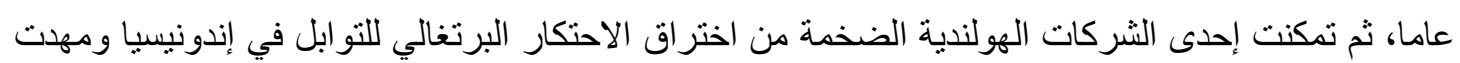
الطريق للاحتلال الهولندي الذي بدأ في القرن الخامس عشر واستمر لمدة 350 عاما. و استطاع مسلمو إندونيسيا أن يحافظوا على دينهم، ووصو لا لبداية القرن، استجابت إندونيسيا لحركة الإصلاح الديني الني قادها الثيخ محم عبده في مصر، واعتبر الإسلام السبيل لمناهضة الاحتلال الهولندي،

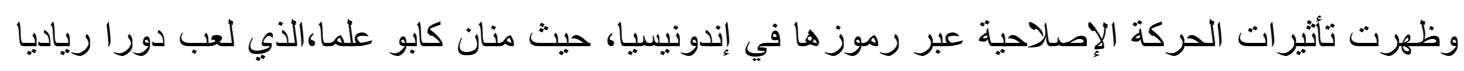

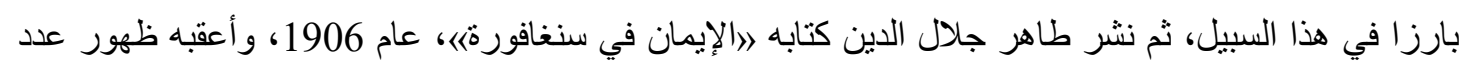

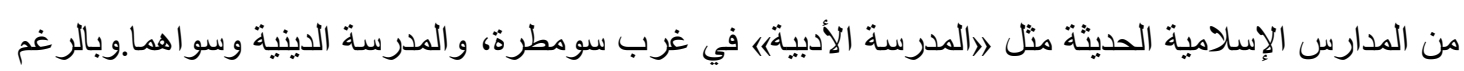

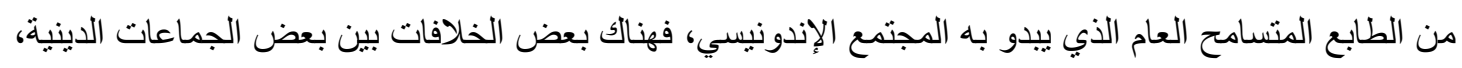

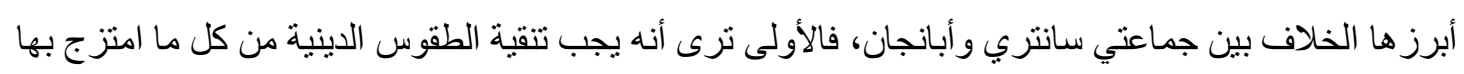

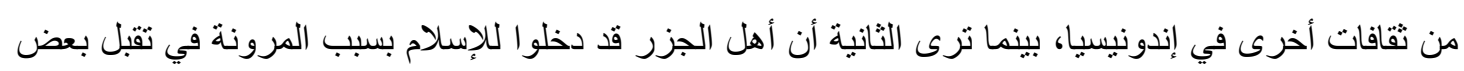
الثكليات في طقوس الاحتفالات الدينية، لكنهم لا يتعرضون لجوهر الدين. أما الخلاف الثاني فهو بين المسلمين

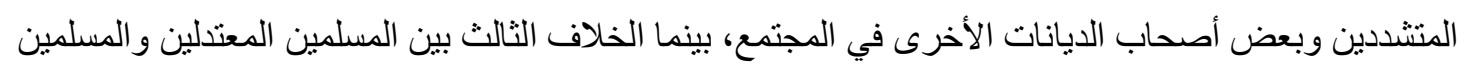
المتشددين المتطرفين، إضافة إلى بعض من حاولوا الترويج لمذاهب جديدة غريبة عن صحيح الدين، مثل جماعة لئن الأحمدية التي منعت في إندونيسيا بفتوى من هيئة العلماء المسلمين، أو بعض المتطرفين الذين قاموا بأعمال تفجيرات و عنف مطلع التسعينيات من القرن الماضي.

\section{الوسطية الإسلامية من خلال جامعة إسلامية}

هنالك جامعات حكومية متخصصة في الدراسات الإسلامية. إن إنشاء الجامعات الإسلامية الحكومية بشكل عام

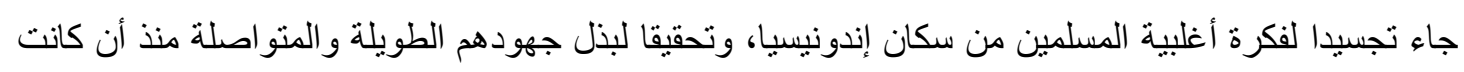
هذه الجامعة تعرف أكاديمية العلوم الدينية (ADIA) عام 1957-1960 م، و هي كانت بمنزلة كلية تابعة للجامعة 
الإسلامية الحكومية التى كان مقر ها في جاكرتا (1960-1963 م)، ثم بدأ اعتبار ها جامعة إسلامية حكومية شريف هداية الله بجاكرتا (IAIN) بدءا من عام 1963 م حتى أصبحت الآن جامعة واسمها الرسمي هو راشريف هداية الله الإسلامية الحكومية بجاكرنا»(UIN) وذللك بناء على قر ار رئيسة الجمهورية الإندونيسية الصادر تحت رقم 31 عام 2002 بتاريخ 20 مايو 2002 م. وتقوم الجامعة بإدارة كليات دينية وعلمبة للمرحلة الجامعية الأولى،مثل كلية التربية والتعليم، كلية الآداب والعلوم الإنسانية، كلية أصول الدين والفلسفة، كلية الثريعة و القانون، كلية الدعوة والاتصال، كلية الدراسات الإسلامية والعربي، بالإضافة إلى برنامج الدراسات العليا

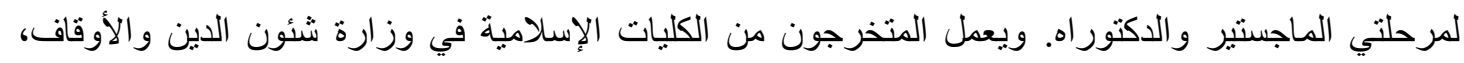

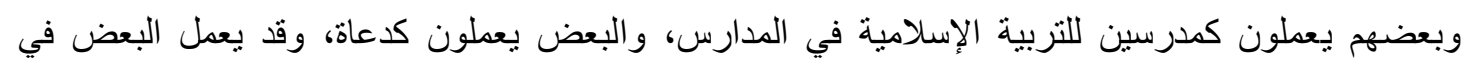
مجالات مختلفة أخرى.

تقوم فلسفة الجامعة على أساس التشديد في ربط النهضة العلمية بالدين، بحيث يتخرج الطلاب وهم على

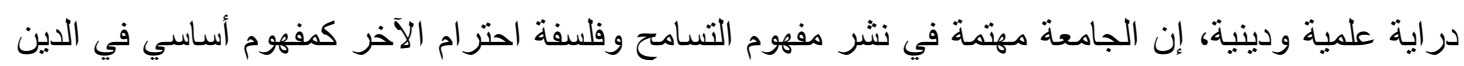
الإسلامي، وكذللك كمفهوم عام لمجتمع متعدد الأعراق والديانات مثل إندونيسيا. لذلك يدرس جميع الطلبة جميع

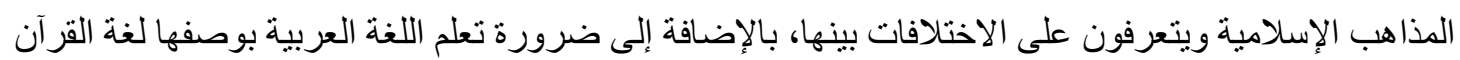

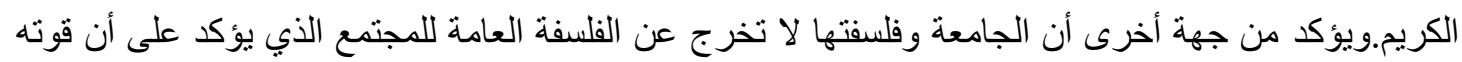
في التنوع، لذللك لا ترى الجامعة أن تضع حدا بين عقيدة الناس وتقاليدهم الاجتماعية، لأن الإسلام دخل إلى البلاد و امتزج مع عاداتهم بوصفه دين سلام، ولهذا قبل أهل إندونيسيا الإسلام.

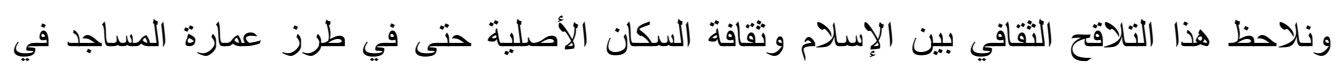

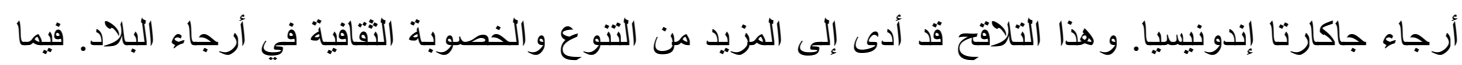

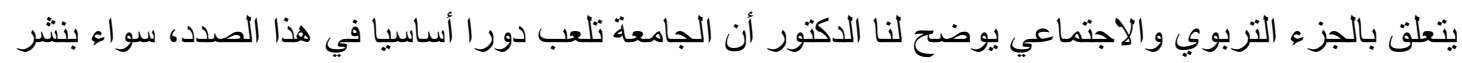

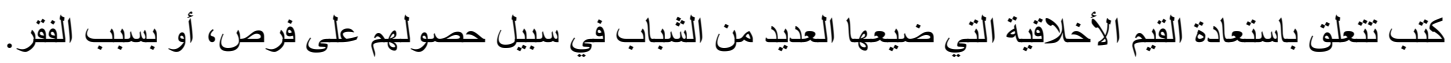
قد انتبهت العديد من المؤسسات الخدمية والإسلامية لهذا الموضوع فبدأت في التخطيط لبر امج نو عية واجتماعية، بحيث يكون لهم دور في تتمية المجتمع وتخليصه من الفقر، وتشجيعهم على العمل التطوعي لخدمة الفقراء لتحسين مستوى أفر اد المجتمع بشكل عام.

\section{الوسطية الإسلامية من خلال المركز الإسلامي}

اختير المركز الإسلامي في جاكرتا في منطقة كانت عبارة عن منطقة خربة تنتشر فيها أنشطة غير الإسله مشروعة، ودعارة، فقرر القائمون على المشروع تحويل المنطقة إلى مركز إسلامي للدء السلوكيات السلبية، وخدمة أهل المنطقة في زيادة وعيهم، وتحفيظهم القرآن الكريم، وتقديم الخدمات لهم، بحيث يتحولون إلى حياة أفضل لهم وللمجتمع. وقد أنشيء المركز في العام2004، عقب انتهاء نثييد المسجد المتاخم، في عام 2001. بدأت الأنشطة بتحفيظ القرآن للاطفال و الثباب، ثم تطورت الخدمات بعمل فصول لتعليم الفتيات مهن يعملن بها ويكسبن قوتهن منها مثل التطريز،والحياكة، وأعمال التجميل، وقص الشعر للسيدات، وغير ذلك من مهن شبيهة.يوضح د. عبد الرشيد أن المحاضرين في الدروس الدينية التي يوفرها المركز لأهل المنطقة أغلبهم

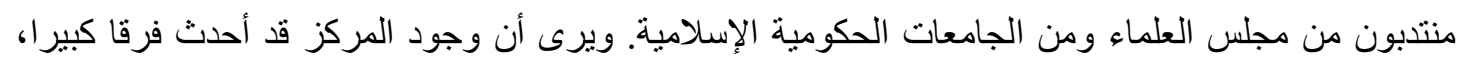
حيث انتهت مظاهر الفساد في المنطقة، والآن يتردد على المركز يوميا ألف شخص يصلون بوم الجمعة إلى ويلى 
6000 شخص، ويتضاعف العدد في الأعياد وفي الاحتفالات الدينية التي يحرص المركز على تفعيلها للترفيه عن أهل المنطقة، حيث تقام أمسيات غنائية وفولكلورية.ويقدم المركز برامج دراسية في إدارة المساجد، وتدريب المدربين، إدارة التخطيط، الإقتصاد الإسلامي، اللغة الإنجليزية، المالية والبنك الإسلامي، برمجة الكومبيونر، و غير ذلك من البر امج التي يستفيد منها عدد كبير من المترددين عليه. و المركز في الحقيقة مشروع خدمي ضخم يضم العديد من الأنشطة الأخرى الخاصة بالثقافة الفنية والتنمية الاجتماعية والدينية في إندونيسيا.ويتسع المسجد الكبير ذو التصميم المعماري الحديث لنحو 20 ألف مصل، وبه مساحة ضخمة بها نموذج مجسد للكعبة المشرفة، حيث يقوم القائمون ى المركز بتدريب الر اغبين في أداء مناسلك الحج او العمرة تدريبا عمليا على المناسك حتى لا يفاجأون بأي شيء عند وصولهم إلى مكة.كما يضم المركز مكتبة ضخمة تضم آلاف الكتب في فروع المعرفة العامة، إضافة إلى الجزء الأكبر منها الذي يتعلق بالتعاليم الإسلامية الدينية والتي يتردد عليها الثباب

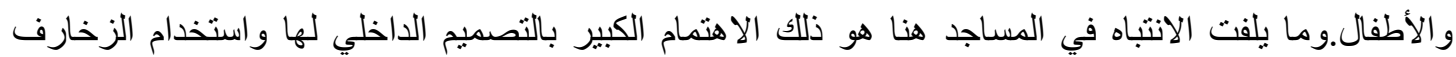
الدقبقة في الجدران و الأسقف، وخصوصا في القباب. أما العمارة الخارجية فهي مصدمة بحيث تبدو مزيجا من العمارة الإسلامية والعربية وبين الثقافة المحلية، وهو ما لاحظناه في مسجد الاستقلال الذي يعد أكبر مساجد

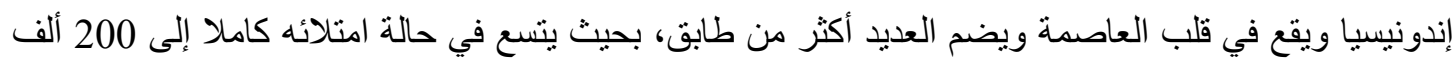
شخص، و هو ما يحدث في الأعياد، بينما يتسع صحنه الداخلي فقط لخمسين ألف مصل، يملأونه في أيام الجمع.

\section{الوسطية الإسلامية من خلال مجلس العلماء}

هناك مجلس للعلماء الإندونيسي يلعب دورا مهما في تسيير شئون المسلمين. حيث يجتمعون في اجتماع لجنة الفتوى التي كانت عقدت جلسة طارئة لبحث موضوع مستجد أثثير في الصحف الإندونيسية فحواه هو أن القبلة في إندونيسيا قد تغير اتجاهها وفقا لبعض من قالوا إن لأرض قد تعرضت لبعض التغيرات بسبب

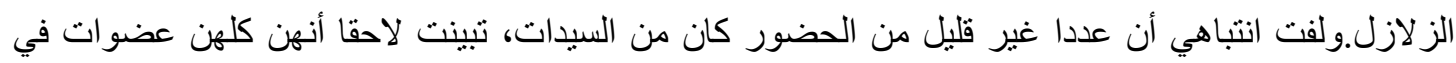
لجنة الفتوى، وفي مجلس العلماء، وهو ما سوف يثير تساؤلا عن دور المرأة في إندونيسيا، والذي بدا لنا دورا رئيسيا، فهي لها وضعها، وكثير ا ما تتكفل الفتاة بنفقات بعض إخوتها لو كان العدد كبيرا، و هناك جماعات من العرقيات الإندونيسية لاتز ال الأم هي التي تلعب فيها الدور المركزي وليس الرجل. إن المجلس يجسد مظلة كبيرة للمر اكز و الهيئات الإسلامية الرئيسية في إندونيسيا والتي يبلغ عددها 36

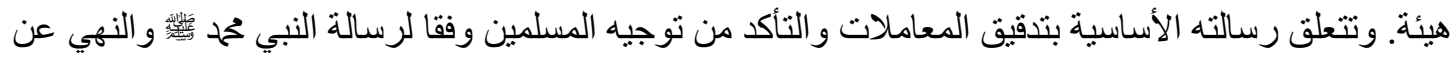
المنكر. إضافة إلى الدور المرجعي في الضبط والإشراف على المؤسسات الإسلامية المختلفة، والقيام بدور الفتوى فيما يختلف عليه خصوصا في بيان حرمة بعض المواد الغذائية أو مستحضرات التجميل أو الأدوية وفقا لمكوناتها وبناء على فحوص خاصة تصدر بناء عليها الفتوى، إضافة أيضا لمعاملات البنوك و الثشئون المالية في الدولة.

ويلعب المجلس دورا في تقييم بعض الجماعات الدينية التي تتبع البدع وتحيد عن صحيح الإسلام و أثنهر تلك الفرق فرقة الأحمدية التي كانت تدعي أن لها نبيا، ولها كتاب خاص ويقوم أتباعها ببعض الطقوس الخاصة مما جعل المجلس يصدر بيانا برفض هذه الجماعة وتحريم تبعيتها. يقول الحاج صبر ا إن السبب في لي لئ

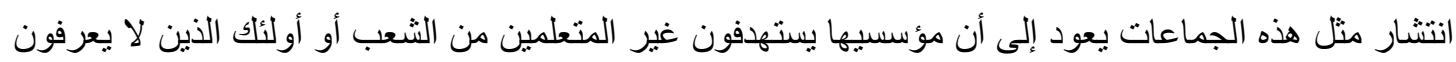
جيدا عن الدين الإسلامي لعدم معرفتهم للقر اءة وللغة العربية.ويقدم مجلس العلماء برامج توعية دينية تقدم تفسير 
القرآن الكريم والحديث وتعلم قراءة القرآن واللغة العربية و اللغة الإنجليزية، من خلال بر امج ودروس دينية في المساجد ،أو في التلفزيون، وتشجيع إنشاء المدارس الإسلامية التي تتضمن الدراسات الإسلامية في مناهجها و التي بلغ عددها حتى الآن 14000 مدرسة. ويتحمل المجلس أيضا تنظيم شئون بناء المساجد التي يبلغ عددها 700 ألف مسجد في أرجاء إندونيسيا وتنظيم شئون الحج، حيث تعتبر بعثة الحج الإندونيسية الأكبر في العالم حيث يؤدي مناسك الحج من خلالها سنويا 210 آلاف حاج.ويتخذ المجلس صيغة مؤسسة دولية لها علاقات مع بع لعاه المجالس الثبيهة في ماليزيا وسنغافورة وباقي دول آسبا، وتعتمد في الفتاوي على اجتهادات أعضاء المجلس, بعد بحث أي مسألة مع ممثلين من الهيئات الإسلامية الست وثلاثثن الموجودة، مما يعني أن القرار في الفتاوي قرار جماعي وليس فرديا. إن المجتمع الإندونيسي هو نموذج يقدم صورة إيجابية للمسلمين، في التسامح وقبول الآخر ، والإنتاج و العمل، والتنمية، ونحن نحتاج إلى أن نتعلم منهم، ومن كل تجربة إيجابية وخيرة و إنسانية، و لا تستثنى التجربة الإندونيسية من ذلك، فمثل هذه المجتمعات النبيلة لا يبقى في الذاكرة منها سوى صورة ولتهن للخضرة

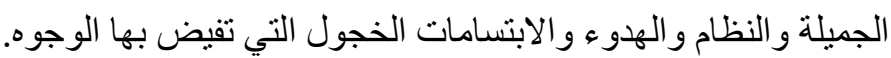

الخاتمة:

وقفنا في هذه الورقة على بعض تجليات التعددية في ظل الوسطية الإسلامية كما تبرز من خلال النصوص القرآنية والحديثية، ولا نحسب أننا قد أتينا عليها جميعا، لكننا ركزنا على أهمها من وجهة نظرنا، فالموضوع جد طويل ويحتاج إلى كتابات عديدة وعميقة ومتأنية تقرب من تحديد معالم قضية التعدد وذلك بتوفر عنصر أساسي، ألا و هو ضرورة قراءة كل النصوص القرآنية والحديثية الني لها علاقة مباشرة وغير مباثرة بمسألة الاختلاف ومظاهره. يمكن القول بأن الإسلام يقر التعددية بكل صور ها وألوانها ويبين للمسلمين وغير المسلمين أن الحياة تتسع للموافق والمخالف. ونستطيع أن نخلص بأن الاختلاف حقيقة كونية وفريضة شرعية أقرها الإسلام. فإذا وصلنا إلى هذه النتيجة أيقا أن الذين يتحدثون عن زوال هذا الاختلاف أو نفي وجوده أصلا وعن اجتماع الناس على رأي واحد غير منصوص عليه بنص قطعي الثبوت قطعي الدلالة، وهو الذي يمثل ثوابت الإسلام وأركانه، كلامهم يحتاج إلى نظر حيث يصعب إثباته أو تطبيقه، وهو ما لم يحدث حتى في عهد أصحاب النبي الذين اختلفو الفيا و الرسول بينهم ينتزل عليه الوحي. فالإنسان لا يمل من هذا الاختلاف سواء كان في أمور شرعية أو أمور حياتية

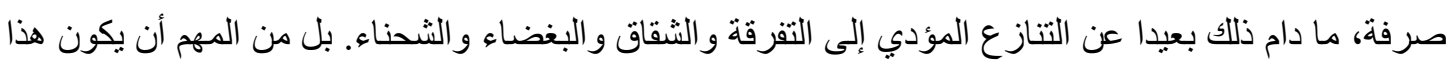
الاختلاف منهج حياة بطبقه الزوج و الزوجة في بيتهما مع أولادهما وتطبقه المؤسسات على اختلافها وتنوعها بهاه

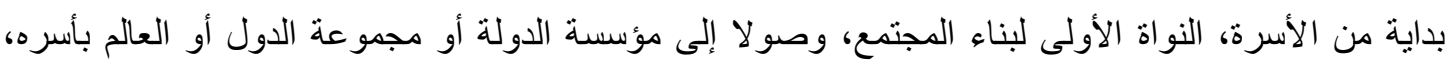
وذلك لترسيخ قيم الحوار والتسامح اللذان يعتبران من أرقى الروابط السامية للاجتماع البشري والعلاقات 


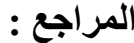

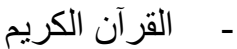

$$
\begin{aligned}
& \text { - - محيح مسلم، طبعة دار إحياء التراث العربي، بيروت. } \\
& \text { - مسند أحمد بن حنبل، مؤسسة قرطبة القاهرة. } \\
& \text { - - تفسير ابن كثير طبعة دار الفكر،بيروت } 1401 \text { هـ. } \\
& \text { - } \\
& \text { - التاريخ الكبير، البخاري، دار الفكر، تحقيق السيد هاثم الندوي } \\
& \text { - تاريخ الطبري، دار الكتب العلمية، بيروت. }
\end{aligned}
$$

- مجموعة الوثائق السياسية للعهد النبوي والخلافة الراثدة، محمد حميد الله الحيدر آبادي، طبعة القاهرة

$$
\text { سنة 1956. }
$$

- - توماس آرنولد ، الدعوة إلى الإسلام: بحث في تاريخ نشر العقبدة الإسلامية، نقله إلى العربية د. حسن

$$
\text { إبر اهيم حسن وزميلاه، طبعة القاهرة. }
$$

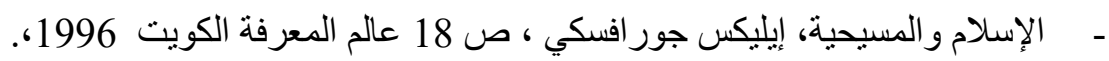

- ـ التوجه الاجتماعي في الإسلام، الثيخ أبو زهرة 21/2 مجمع البحوث الإسلامية القاهرة 1391هـ.

- الاتجاه إلى حوار إسلامي غربي، د.أحمد كمال أبو المجد جريدة الحياة اللندنية 21 مارس 1997 ص 